Linköping Studies in Science and Technology

Dissertations, No. 1612

\title{
Dry Clutch Modeling, \\ Estimation, and Control
}

Andreas Myklebust

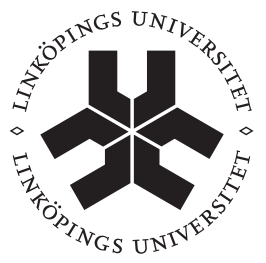

\section{Linköping University INSTITUTE OF TECHNOLOGY}

Department of Electrical Engineering

Linköping University

SE-581 83 Linköping, Sweden

Linköping 2014 
Linköping Studies in Science and Technology

Dissertations, No. 1612

This is a Swedish Doctoral Dissertation.

A Doctor's degree comprises 240 ECTS credits (4 years of full-time postgraduate studies), of which at least 120 ECTS credits constitute a doctoral dissertation.

Andreas Myklebust

andreas.myklebust@liu.se

www.vehicular.isy.liu.se

Division of Vehicular Systems

Department of Electrical Engineering

Linköping University

SE-581 83 Linköping, Sweden

Copyright (c) 2014 Andreas Myklebust, unless otherwise noted.

All rights reserved.

Myklebust, Andreas

Dry Clutch Modeling,

Estimation, and Control

ISBN 978-91-7519-261-1

ISSN 0345-7524

The graph on the cover is based on data from Figure 4 in Paper D. Actuator position, time, and clutch torque are on the axes and the coloring depends on the clutch disc temperature. The details are left as an exercise to the reader. The drawing in the background pictures a clutch disc.

Typeset with $\mathrm{AT}_{\mathrm{E}} \mathrm{X} 2 \varepsilon$

Printed by LiU-Tryck, Linköping, Sweden 2014 
"A mathematical model does not have to be exact; it just has to be close enough to provide better results than can be obtained by common sense."

- Herbert A. Simon 



\section{Abstract}

Increasing demands on comfort, performance, and fuel efficiency in vehicles lead to more complex transmission solutions. One such solution is the Automated Manual Transmission (AMT). It works just like an ordinary manual transmission but the clutch and the gear selection are computer controlled. In this way high efficiency can be accomplished with increased comfort and performance. To be able to control and fully utilize an AMT, it is of great importance to have knowledge about how torque is transmitted in the clutch. The transmitted torque in a slipping dry clutch is therefore studied in a series of experiments with Heavy Duty Trucks (HDT). It is shown that material expansion with temperature can explain torque variations up to $900 \mathrm{Nm}$ for the same clutch actuator position. A dynamic clutch temperature model that can describe the torque variations is developed. The dynamic model is validated in experiments, and shown to reduce the error in transmitted torque from $7 \%$ to $3 \%$ of the maximum engine torque compared to a static model. Since all modeling, parameter estimation, and validation are performed with production HDTs, i.e. production sensors only, it is straightforward to implement the model in a production HDT following the presented methodology.

The clutch model is extended with lock-up/break-a-part dynamics and an extra state describing wear. The former is done using a state machine and the latter uses a slow random walk for a parameter corresponding to the thickness of the clutch disc. Two observability analyses are made: one with production sensors, and one with a torque sensor in addition to the production sensors. The analyses show that, in both cases, the temperature states and the wear state are observable both during slipping of the clutch and when it is fully closed. The latter is possible since a sensor measures the actuator position. The unknown offset in the torque sensor is possible to observe (at all times) if the model is further augmented with engine inertia dynamics. An Extended Kalman Filter (EKF) is developed and evaluated on measurement data for both cases. The estimated states converge from poor initial values, enabling prediction of the translation of the torque transmissibility curve and sensor offset. The computational complexity of the EKF is low and it is thus suitable for real-time applications.

The clutch model is also integrated into a driveline model capable of capturing vehicle shuffle (longitudinal speed oscillations) and engine torque fluctuations. Parameters are estimated to fit an HDT and the complete model shows good agreement with data. It is used to show that the effect of thermal expansion, even for moderate temperatures, is significant in clutch control applications. One such application is micro-slip control. A control structure has been made and the basic components are a reference-slip calculator, an LQ controller and an EKF that can compensate for the thermal dynamics of the clutch. The controller isolates the driveline from the engine oscillations without dissipating more heat than the clutch can handle. An analysis shows a noticeable fuel consumption increase. Nonetheless, the real benefits of micro-slip control will only be evident when combined with other cost-reducing changes in the powertrain. The feasibility of a micro-slip control system for a dry clutch HDT has been proven. 



\section{PopuläRVETEnskaplig SAmmanfattning}

Ökande krav på komfort, prestanda och bränsleeffektivitet i fordon leder till mer komplexa växellådslösningar. En möjlig lösning är en så kallad automatiserad manuell växellåda, även kallad robotväxellåda. En sådan fungerar precis som en vanlig manuell växellåda fast kopplingen och växelväljaren styrs automatiskt av en dator. Denna lösning ger samma höga effektivitet i växellådan som en vanlig manuell växellåda men med ökad komfort och prestanda, förutsatt att växellådan styrs på ett bra sätt. För att kunna programmera styrdatorn så att den presterar bättre än en mänsklig förare är det viktigt att känna till hur kopplingen överför vridmoment från motor till växellåda. Därför har det överförda vridmomentet studerats i tunga lastbilar försedda med automatiska torrkopplingar. Mätningar har visat att vridmomentet kan variera med upp till $900 \mathrm{Nm}$ för en given position på kopplingens ställdon. Momentvariationen har visats bero på materialexpansion på grund av värmeutvecklingen som sker när kopplingen slirar. För att kunna förutse materialexpansionen har en modell utvecklats över hur kopplingen värms upp och expanderar. Alla experiment som behövts för att utveckla modellen samt validera den har utförts på produktionslastbilar och det är därför rättframt att anpassa modellen till önskvärt fordon genom att följa den metodik som presenteras i avhandlingen.

Om simuleringen av modellen startas ifrån ett felaktigt tillstånd och/eller modellen inte är helt exakt kommer simuleringen att resultera i ett felaktigt värde. För att motverka detta kan en observatör användas. En observatör justerar simuleringen så att felet mellan mätsignal och modellerat värde blir så litet som möjligt. På detta sätt kan styrsystemet, med hjälp av modellen, beräkna värdet på variabler som inte är direkt mätbara. I detta fall rör det sig om temperaturerna i kopplingen samt kopplingslamellens tjocklek. Det senare är viktigt då slitage minskar lamellens tjocklek. En observatör har designats och testats framgångsrikt på data. Detta betyder att med observatören är det möjligt att förutse, i växellådans styrenhet, hur kopplingens vridmoment varierar med temperatur och slitage.

Kopplingsmodellen har även integrerats i en större fordonsmodell som beskriver hur en lastbil beter sig i längdled. Fordonsmodellen har använts för att påvisa vikten av att kompensera kopplingsstyrningen för värmeeffekterna vid en start. Fordonsmodellen har sedan vidareutvecklats med en modell för det pulserande vridmoment en förbränningsmotor producerar. Dessa pulsationer ger upphov till oscillationer i motorhastigheten och är viktiga att beakta när slirhastigheten i kopplingen är av motsvarande storlek. En styralgoritm som klarar av att kontinuerligt hålla kopplingens slirhastighet låg utan att låsa upp kopplingen, en så kallad mikroslip-regulator, har utvecklats med hjälp av fordonsmodellen. Fördelen med mikroslip-regulatorn är att växellådan, och i förlängningen drivhjulen, isoleras från motorns pulserande vridmoment eftersom kopplingen överför moment genom friktion och inte genom pulserande förbränningar. Nackdelen är att mekanisk energi omvandlas till värme i kopplingen vilket leder till ökad bränsleförbrukningen samt högre temperaturer, som kan vara skadliga för kopplingen. Temperaturerna i kopplingen visas vara hanterbara medan bränsleförbrukningen måste vägas mot andra kostnadsbesparande åtgärder som möjliggörs i drivlinan. Hursomhelst är mikroslip-reglering är en möjlig strategi för tunga lastbilar. 



\section{ACKNOWLEDGMENTS}

I would like to thank my supervisor Lars "Lasse" Eriksson for showing me, and walking me through the very curvy path of PhD-studies. I would also like to thank Lars Nielsen for valuable feedback as my stand-in supervisor during the last two months of work (i.e. during June). Additional appreciation goes to Torkel Glad for proofreading the last article, and to David Mattsson and Neda Nickmehr for proofreading the thesis.

A dissertation is not formed by writing alone (at least not in this field), thoughtful experiments and conclusions are also necessary. For aid in these matters I would like to thank some people at Scania CV AB: Foremost Karl Redbrandt (during the first years) and Anders Larsson (during the last year) for help with setting up the experiments as well as interesting discussions. Also Jörgen Hansson is acknowledged for some early experiments, and Kristian Hellgren is acknowledged for some valuable clutch $^{1}$ conversations.

And at last, I would like to thank Elin Julin for help with the cover design, endless moral support, and for doing roughly 80-90\% of all household work during the last two months of work. I hope we can continue with this division of labor, even though I now will have time for some vacation...

\footnotetext{
${ }^{1}$ The word clutch is used 933 times in this thesis, including the cover.
} 



\section{Contents}

1 Introduction 1

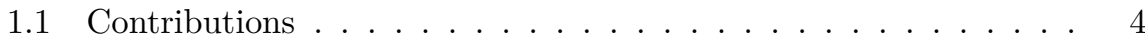

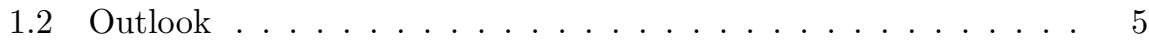

1.3 Publications ................... 6

2 Introduction to Clutch and Driveline 7

2.1 Clutch Operation . . . . . . . . . . . . . . . 7

2.2 The Idea of Micro Slip Control . . . . . . . . . . . . . . . . . . . 9

2.3 Review of Clutch and Driveline Models . . . . . . . . . . . . . . 10

2.3.1 Driveline Models . . . . . . . . . . . . . . . . . 10

2.3.2 Clutch Models .................. . . 11

2.4 Introduction to Micro-Slip Control . . . . . . . . . . . . . . . . 12

3 Experimental Observations and Model Structure $\mathbf{1 5}$

3.1 Experimental Platform . . . . . . . . . . . . . . . . . . 15

3.2 Motivating Experiment . . . . . . . . . . . . . . . . . . . 16

3.3 Actuator Dynamics . . . . . . . . . . . . . . . . . 17

3.4 Clutch Variables . . . . . . . . . . . . . . . . . . 19

3.5 Wear . . . . . . . . . . . . . . . . 20

3.6 Slip . . . . . . . . . . . . . . . . . . . . 20

3.7 Rotational Speed . . . . . . . . . . . . . . . . . . 21

3.8 Temperature . . . . . . . . . . . . . . . . . 22

3.8.1 Vehicle Speed Dependency . . . . . . . . . . . . 25

3.8.2 Engine Speed Dependency . . . . . . . . . . . . . 26

3.9 Model Summary and Usage in Papers . . . . . . . . . . . . . . . 27

References . . . . . . . . . . . . . . . . . 28

$\begin{array}{ll}\text { Publications } & 33\end{array}$

A Torque Model with Fast and Slow Temperature Dynamics of a Slipping Dry Clutch $\quad 35$

1 Introduction . . . . . . . . . . . . . . . . . . 38 
2 Experimental Setup . . . . . . . . . . . . . . . . . 39

3 Modeling Outline . . . . . . . . . . . . . . . . . 39

4 Slip dependency . . . . . . . . . . . . . . . . . . . . . . . . 40

5 Temperature Effects and Models . . . . . . . . . . . . . . . 42

5.1 Material Expansion Analysis . . . . . . . . . . . . 43

5.2 Expansion Model . . . . . . . . . . . . . . . . . . 44

5.3 Including Fast Dynamics . . . . . . . . . . . . . . . . 46

6 Model Validation . . . . . . . . . . . . . . . . . . . . 48

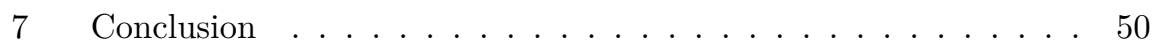

References ........................ 52

B The Effect of Thermal Expansion in a Dry Clutch on Launch Control

1 Introduction . . . . . . . . . . . . . . . . . 56

2 Driveline Model . . . . . . . . . . . . . . . . 57

2.1 Internal Combustion Engine . . . . . . . . . . . . 58

$2.2 \quad$ Clutch . . . . . . . . . . . . . . 58

2.3 Transmission . . . . . . . . . . . . . . 61

2.4 Propeller Shaft . . . . . . . . . . . . . . . 61

$2.5 \quad$ Final Drive . . . . . . . . . . . . . . 61

2.6 Drive Shafts . . . . . . . . . . . . . . 61

2.7 Vehicle Dynamics . . . . . . . . . . . . . . 62

3 Parameter Estimation . . . . . . . . . . . . . . . . . 62

4 Model Validation . . . . . . . . . . . . . . . . . 65

5 Thermal Effect on Launching . . . . . . . . . . . . . . . 66

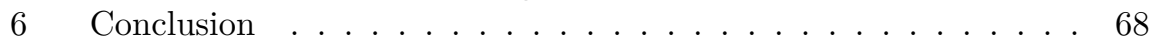

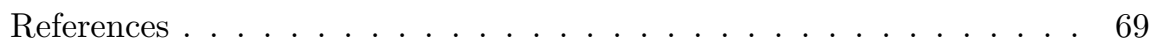

C Modeling, Observability, and Estimation of Thermal Effects and Aging on Transmitted Torque in a Heavy Duty Truck with a Dry Clutch

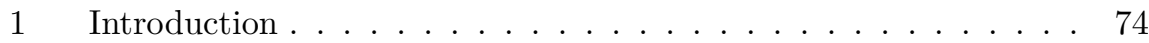

$1.1 \quad$ Outline . . . . . . . . . . . . . . 74

1.2 Survey of Clutch Models . . . . . . . . . . . . . . 74

1.3 Contributions . . . . . . . . . . . . . 76

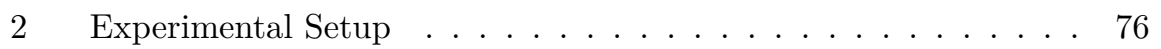

3 Clutch Model . . . . . . . . . . . . . . . . . . . . . 78

3.1 Lock-Up/Break-Apart Logic . . . . . . . . . . . . . . . . 78

$3.2 \quad$ Slipping Torque Model Structure . . . . . . . . . . . . . . 79

3.3 Slip dependency . . . . . . . . . . . . . . . . . . . . 80

3.4 Temperature Effects and Models . . . . . . . . . . . . 81

3.5 Tuning Methodology . . . . . . . . . . . . . . . . . . . 88

$3.6 \quad$ Model Summary . . . . . . . . . . . . . . . . . . . . . 88

3.7 Clutch Model Validation . . . . . . . . . . . . . . 88

4 Observer . . . . . . . . . . . . . . . . . . . 90 
4.1 Observability .................. . . 92

4.2 Observer Selection and Precautions . . . . . . . . . . . 93

4.3 Selection of EKF Covariance Matrices . . . . . . . . . . . 94

5 Observer Evaluation . . . . . . . . . . . . . . . . . 95

6 Conclusion ........................ 97

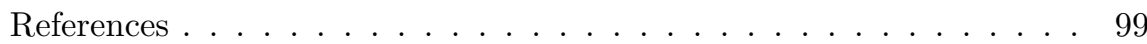

D Thermal Clutch Model Observability and Observer Effects of a Torque Sensor in the Powertrain 103

1 Introduction . . . . . . . . . . . . . . . . . . . . 106

1.1 Outline and Contributions . . . . . . . . . . 106

2 Experimental Setup . . . . . . . . . . . . . . . . 108

3 Clutch Model . . . . . . . . . . . . . . . . . . . 109

3.1 Lock-Up/Break-Apart Logic . . . . . . . . . . . . . . . . . 110

3.2 Slipping Torque Model Structure . . . . . . . . . . . . . . 110

3.3 Torque Sensor . . . . . . . . . . . . . . . . . . 113

3.4 Clutch Model Validation . . . . . . . . . . . . . . 114

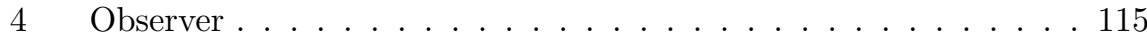

4.1 Observability .................. 116

4.2 Observer Selection and Precautions . . . . . . . . . . . 118

4.3 Selection of EKF Covariance Matrices . . . . . . . . . . . 119

5 Observer Evaluation . . . . . . . . . . . . . . . . . 119

6 Conclusions ........................ 120

References . . . . . . . . . . . . . . . . . 121

E Dry Clutch Micro-Slip Control and Temperature Considerations

1 Introduction . . . . . . . . . . . . . . . . . 126

1.1 Contributions . . . . . . . . . . . . . . 127

2 Model .......................... 128

2.1 Control Model . . . . . . . . . . . . . . . . 131

2.2 Oscillating Torque Model . . . . . . . . . . . . . 132

3 Controller . . . . . . . . . . . . . . . . . . 137

3.1 Reference Slip . . . . . . . . . . . . . . 139

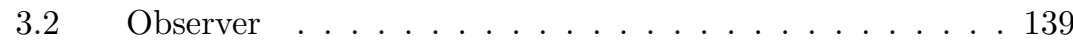

3.3 LQ-Design . . . . . . . . . . . . . . . . . . 139

4 Controller Evaluation . . . . . . . . . . . . . . . . 143

5 Temperature Considerations . . . . . . . . . . . . . . . 144

6 Fuel Consumption . . . . . . . . . . . . . . . . . . . 149

7 Conclusions . . . . . . . . . . . . . . . 150

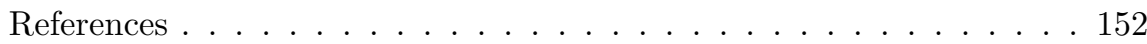


F Road Slope Analysis and Filtering for Driveline Shuffle Simulation

1 Introduction . . . . . . . . . . . . . . . . . 158

2 Powertrain model . . . . . . . . . . . . . . . . . . 158

2.1 Internal Combustion Engine . . . . . . . . . . . . . . 159

$2.2 \quad$ Clutch . . . . . . . . . . . . . . . . . . . . 159

2.3 Transmission . . . . . . . . . . . . . . . . . 161

2.4 Propeller Shaft . . . . . . . . . . . . . . . . . . . . . 161

$2.5 \quad$ Final Drive . . . . . . . . . . . . . . . . . . . . 161

2.6 Drive Shafts . . . . . . . . . . . . . . . . . . . 162

2.7 Vehicle Dynamics . . . . . . . . . . . . . . . . . . . . 162

2.8 State-Space Model . . . . . . . . . . . . . . . . . . . . 164

2.9 Linearization . . . . . . . . . . . . . . . . . . . . . 165

2.10 Model Validation . . . . . . . . . . . . . . . . . 167

3 Slope Signal Effect on Simulation . . . . . . . . . . . . . . . . 167

4 Road Frequency . . . . . . . . . . . . . . . . . . . . . . . 170

$5 \quad$ Filter Design . . . . . . . . . . . . . . . . . . 171

6 Results . . . . . . . . . . . . . . . . . . . . . 173

7 Conclusions . . . . . . . . . . . . . . . . . 173

References . . . . . . . . . . . . . . . . . . . . 175 


\section{Chapter 1}

\section{Introduction}

In order to propel a vehicle the engine must be connected to the wheels somehow, and different driveline solutions are available to create this connection. In a common rear-wheel-drive setup, see Figure 1.1, the tractive wheels are connected to a drive shaft each. These drive shafts are, through a final drive (a differential), driven by a propeller shaft that is connected to the transmission. The transmission consists of two parts: First, the actual transmission part where torque and speed is changed by a gear ratio. Second, a connection between the Internal Combustion Engine (ICE) and transmission that is capable of decoupling the speeds between the engine and transmission. Historically comfort was best accomplished with a classical Automatic Transmission (AT) and high efficiency with a Manual Transmission (MT).

An AT actuates different gear ratios through clutches and brakes that locks different parts of planetary gear sets. The coupling between engine and transmission is handled by a torque converter. These two technologies put together, enable seamless gear shifts that can be controlled through simple hydraulics; the AT was put in production as early as 1939 (Nunney, 1998). The drawbacks are lower efficiency, mainly due to pumping of oil in the torque converter, and the increased complexity and cost, compared to an MT.

The MT is coupled to the engine via a clutch that is operated by the driver via the clutch pedal. A simple explanation of the clutch is that it consists of two rotating plates that can be pressed together. When pressed together, friction will arise and transmit a torque between the plates, which acts to reduce the speed difference. See Chapter 2 for a more detailed explanation. Gear selection is realized using two shafts, both with a set of cog wheels, that mesh together. One pair of cog wheels, corresponding to a certain gear, can be engaged by a mechanical linkage connected to the gear lever. This type of transmission has a high efficiency and a simple construction, but requires the clutch to be disengaged during shifting (torque interrupt) and manual input from the driver. For more details on possible transmission constructions see Newton et al. (1996) or Nunney (1998). 


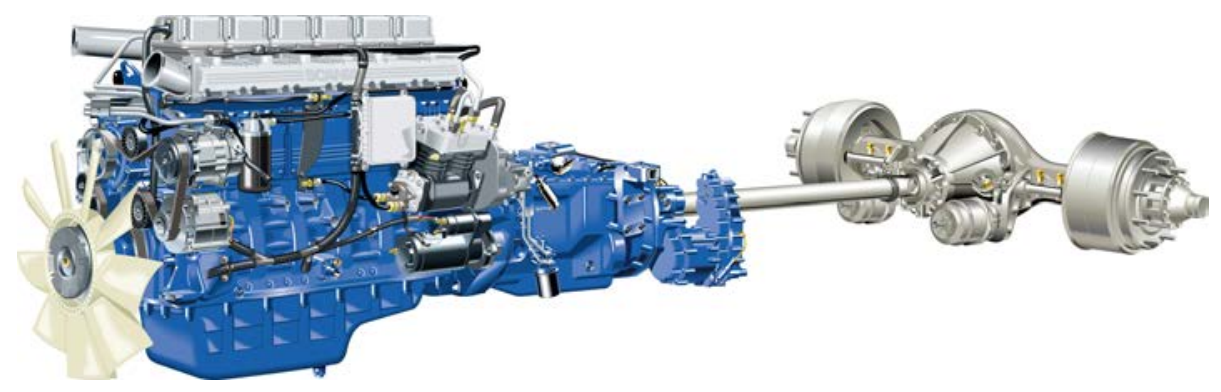

Figure 1.1: A rear-wheel-drive driveline from a Scania truck. The engine, transmission, propeller shaft, differential (final drive), and drive shafts can be seen.

\section{$\mathrm{AMT}$}

Increasing demands on comfort, performance, and fuel efficiency in vehicles lead to more complex transmission solutions. The Automated Manual Transmission (AMT) is one way to combine the best from two worlds. It has the same components and basic operation as an MT but the gear selection and clutch operation have been made automatic. This has become possible thanks to technological advances within actuators and computer controllers. The AMT has the benefits of the MT but without the need of driver attention. However, it still has the drawback of torque interrupt during gear changes. Another option, capable of removing the torque interrupt, is the Dual Clutch Transmission (DCT). The DCT further improves comfort and performance with the drawbacks of increased complexity and cost.

\section{Potential Problems}

An important part in both an AMT and a DCT is clutch control, which has a profound effect on vehicle performance. A poorly controlled clutch can make starts, stops, and gearshifts slow, rough on the hardware, or uncomfortable. An example can be seen in Figure 1.2. In this case driveline oscillations, which cause discomfort, are induced by too rapid disengagement/engagement of the clutch. The driveline oscillations can be seen in both the speed graphs and in the acceleration graphs. This type of oscillations can be clearly felt by the driver and passengers.

\section{Focus OF THE THESIS}

To be able to control the clutch in a fast and comfortable manner without causing excessive wear, it is important to know the torque transmitted in the clutch with high precision. Moreover, the clutch torque is of great interest if the clutch is to be integrated in a powertrain control scheme that is of the common torque 

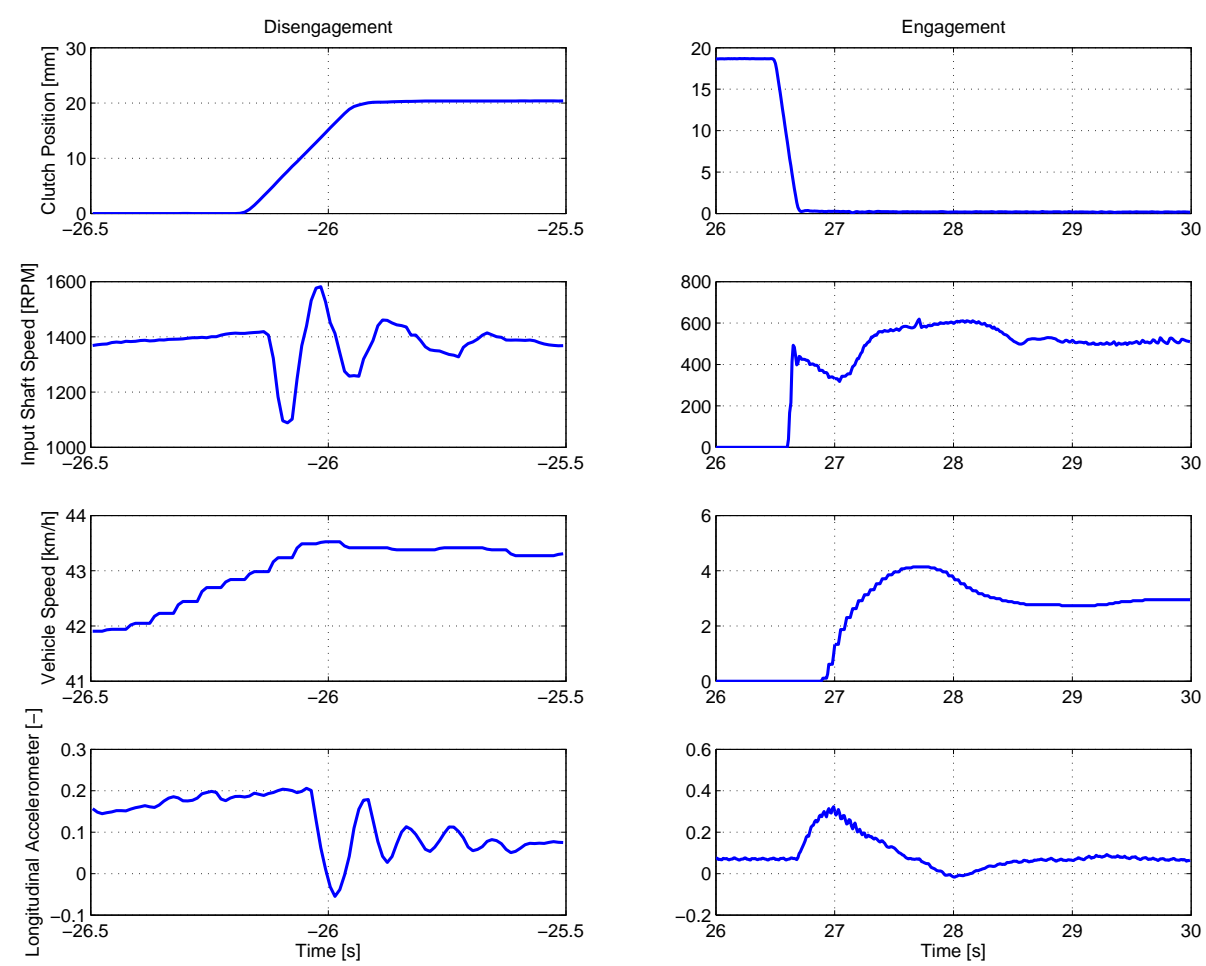

Figure 1.2: The left graphs show measurements of driveline oscillations due to (too) rapid disengagement of the clutch; a scenario possible during gear shifting. The right graphs show the same measurements but in the case of rapid engagement from standstill, which could be the case if the driver wants a quick launch. In both cases the oscillations could clearly be felt by the driver and passenger.

based structure (Eriksson and Nielsen, 2014). Models have come to play an important role in estimation and control of the transmitted torque, since torque sensors still are expensive. Therefore modeling and observation of the clutch torque are main topics here. Since the purpose is to improve clutch control, the resulting model and observer are required to be of low enough complexity to run in real time. Previous experimental investigations of the clutch characteristics (Velardocchia et al., 1999; Moon et al., 2004; Vasca et al., 2011) and (Deur et al., 2012), have been carried out in test rigs equipped with various sensors. Here the experimental platform is limited to production vehicles without additional sensors. On the one hand, this choice imposes certain difficulties in setting up useful experiments. On the other hand, the resulting model and observer can be directly applied to the intended vehicle, in or after production. The goal has been to have a platform for control, and the achievement of this goal is demonstrated through micro-slip control. 


\subsection{COnTRibutions}

A set of experiments for determining significant effects in the clutch and their characteristics has been performed, and has led to a proposed methodology. Since the experimental platforms used here are production vehicles, the proposed methodology can easily be applied to new platforms without the use of additional test equipment. Moreover, the clutch is put in its true thermal environment, between a transmission and a warm combustion engine, which affects the temperature dynamics. The attached papers A-F continue upon the experiments and conclusions of Chapter 3 as well as upon each other in the order they are presented here. The exception is Paper F that is included more as an appendix over the driveline model, although it has its own contributions. The main contributions from each paper are summarized below.

\section{PAPER A}

The main contribution of Paper $\mathrm{A}$ is a novel clutch model that includes the temperature dynamics and thermal effects on the transmitted torque during slipping. The model is developed using a method that utilizes production sensors only. The resulting model is simple enough to run in real time.

\section{PAPER B}

Paper B integrates the clutch model of Paper A into the complete driveline model of Paper F and models clutch lock-up/break-a-part with a simple approach. The complete model is validated against data of vehicle launches. The main contribution is the demonstration of the importance of considering the thermal dynamics during vehicle launch.

\section{PAPER C}

Paper C extends the clutch model of Paper A with a wear parameter corresponding to thinning of the clutch disc. The main contributions are an observability analysis and an observer design for the augmented model. The observability of the augmented model is found to be dependent on the mode of the system. An Extended Kalman Filter (EKF) that can observe the temperatures and the wear parameter is designed and tested on data from production vehicles.

\section{PAPER D}

When a torque sensor with an unknown offset is introduced in the powertrain the work from Paper $\mathrm{C}$ needs to be revised. The model of Paper $\mathrm{C}$ is augmented with a sensor bias and engine inertia dynamics. The main contribution is the revision of the observability analysis and the observer design. The sensor offset is observable at all time while the observability of the other states are unchanged. The EKF is tested on data from an experiment vehicle equipped with a torque sensor. 


\section{PAPER E}

Paper E uses the driveline model of Paper B and augments it with a model for oscillating ICE torque in order to study micro-slip control. The main contributions are the design of a controller structure, including reference slip calculations, and analyses of the temperature and fuel consumption increases. The fuel consumption increase is noticeable but micro-slip control is a possible strategy for a heavy duty truck.

\section{PAPER F}

A driveline model is presented in Paper $\mathrm{F}$ and shown to be appropriate for vehicle longitudinal shuffle simulation. The main contribution is an investigation, using the model, of how and why a discretized slope signal needs to be filtered.

\section{ERRATA}

In Paper $\mathrm{C}$ there is an error in (33). The element on the second row, fourth column should be -1 . With the correct equation, the state $x_{4}$ is observable when the clutch is slipping. This error has been corrected in Paper D.

\subsection{OutLOOK}

Significant temperature effects in the clutch torque have been observed in experiments. A model that explains these effects and an EKF based thereupon has been developed. The EKF is of sufficiently low complexity to be implemented for online use in a vehicle. A case study of micro-slip control has been performed and the EKF was utilized for accurate torque control. This usage of the EKF naturally extends to other areas of clutch control, e.g. launch control and gear changing. Moreover the experimental procedure is general and can be used to modify the model parameterization to suit different setups, e.g. a double clutch. 


\subsection{Publichtions}

The following papers are included in the thesis.

\section{JOURNALS}

- Andreas Myklebust and Lars Eriksson. Modeling, observability and estimation of thermal effects and aging on transmitted torque in a heavy duty truck with a dry clutch. IEEE/ASME Transactions on Mechatronics PP(99):1-12, February 2014. (Paper C)

\section{CONFERENCE PAPERS}

- Andreas Myklebust and Lars Eriksson. Torque model with fast and slow temperature dynamics of a slipping dry clutch. In 2012 IEEE Vehicle Power and Propulsion Conference. October 2012. (Paper A)

- Andreas Myklebust and Lars Eriksson. The effect of thermal expansion in a dry clutch on launch control. In 7th IFAC Symposium on Advances in Automotive Control. September 2013. (Paper B)

- Andreas Myklebust and Lars Eriksson. Road slope analysis and filtering for driveline shuffle simulation. In 2012 IFAC Workshop on Engine and Powertrain Control, Simulation and Modeling. October 2012. (Paper F)

\section{SubMitTED}

- Andreas Myklebust and Lars Eriksson. Thermal clutch model observability and observer effects of a torque sensor in the powertrain. Submitted to IEEE/ASME Transactions on Mechatronics. (Paper D)

- Andreas Myklebust and Lars Eriksson. Dry clutch micro-slip control and temperature considerations. Submitted to IEEE/ASME Transactions on Mechatronics. (Paper E) 


\section{Chapter 2}

\section{Introduction to Clutch and Driveline}

This chapter gives some background to Chapter 3 and the papers. First, the basic operation of a clutch is explained. Second, the concept of micro slip, an application studied in Paper E, (Myklebust and Eriksson, 2014c), is explained. Third, introductory literature reviews are given on the subjects of driveline modeling, clutch modeling, and micro-slip control. More details from the literature are given in Chapter 3 and the papers.

\subsection{Clutch Operation}

A schematic of the dry clutch and actuator studied in this thesis is found in Figure 2.1. It has an electro-hydraulic actuator and the clutch construction is typical for a dry clutch. Double clutches have slightly altered constructions but the main principle is the same.

The electric motor rotates a worm gear that pushes into the hydraulic fluid; in an MT the clutch pedal would do this. When the opening to the reservoir is passed the hydraulic fluid pushes on a piston that through a lever pulls the throw-out bearing away from the clutch; the depicted clutch is hence called a pull-type clutch.

The throw-out bearing pulls on the fingers of the diaphragm (also called belleville, washer, slotted disc) spring. This spring is radially pivoted and angularly fixed to the clutch cover that is bolted to the flywheel. The bolting of the clutch cover pre-loads the diaphragm spring so that it exerts a force on the pressure (or push) plate and thus clamps the clutch disc between the pressure plate and the flywheel. The pressure plate is angularly fixed to the clutch cover and thereby to the flywheel as well. When the throw-out bearing is pulling the fingers of the diaphragm spring, load is taken off the pressure plate. As the pressure plate exerts less clamp load, the cushion (or flat) spring inside the 


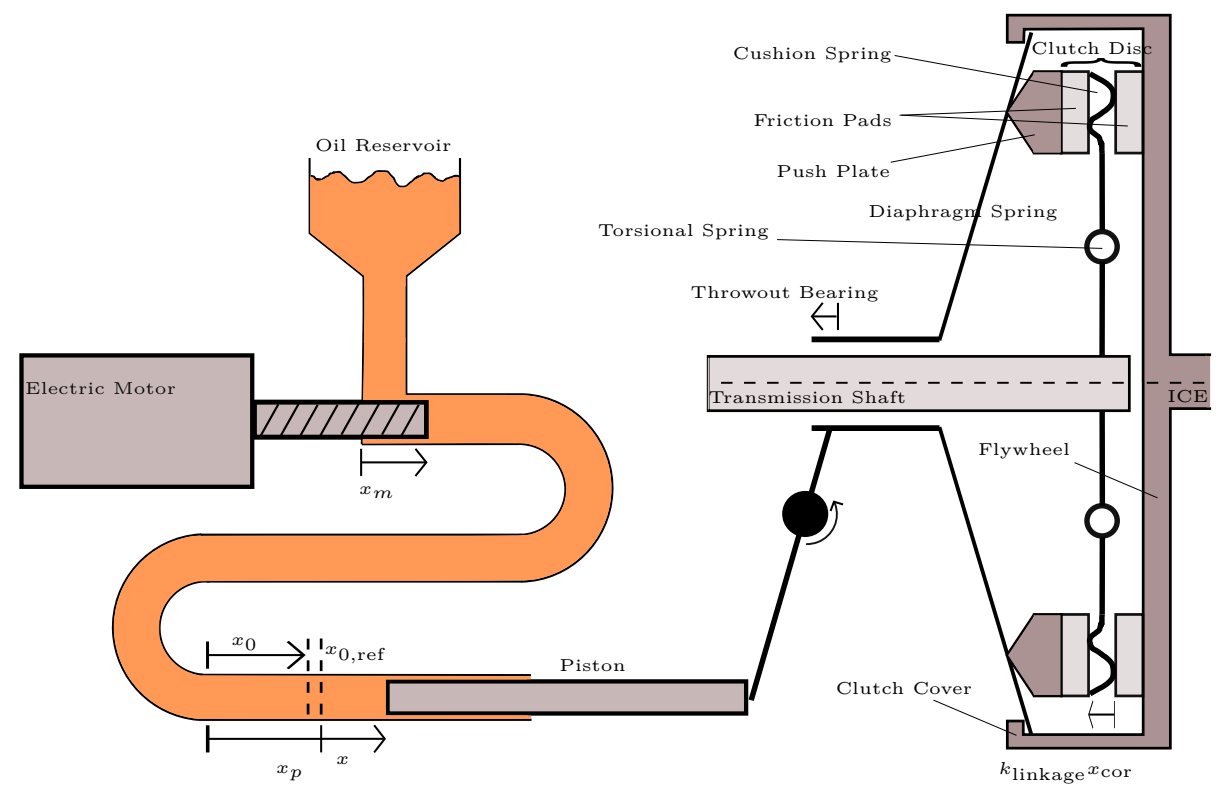

Figure 2.1: A schematic over the actuator and the dry single-plate pull-type clutch studied here. $k_{\text {linkage }}$ is the combined ratio of all levers between the piston and the push plate. Sometimes the measurement $x$ is used instead of $x_{p}$ as a wear compensated piston position that is in the same range as $x_{m}$.

clutch disc expands leading to a new equilibrium position for the clutch linkage. The connection between positions, spring characteristics, and bearing force can be seen in Figure 2.2. Through this arrangement a certain actuator position will correspond to a certain clamp load, which facilitates control, especially in the manual case.

The clutch disc is angularly fixed to the transmission input shaft and can therefore rotate with a different speed than the engine and flywheel. When the clamp load becomes greater than zero a friction force will arise if there is a speed difference. This force will result in a torque around the crank shaft and input shaft working to reduce the speed difference. With a larger normal force a larger torque will be transmitted and if the speed difference gets reduced to zero the clutch will lock up, i.e. static friction will take place. When locked up, the clutch acts as a solid unit and transmits the engine torque as long as it does not exceed the stiction torque. For more detailed descriptions of how a clutch works see Mashadi and Crolla (2012); Newton et al. (1996); Dolcini et al. (2010) or Vasca et al. (2011). 


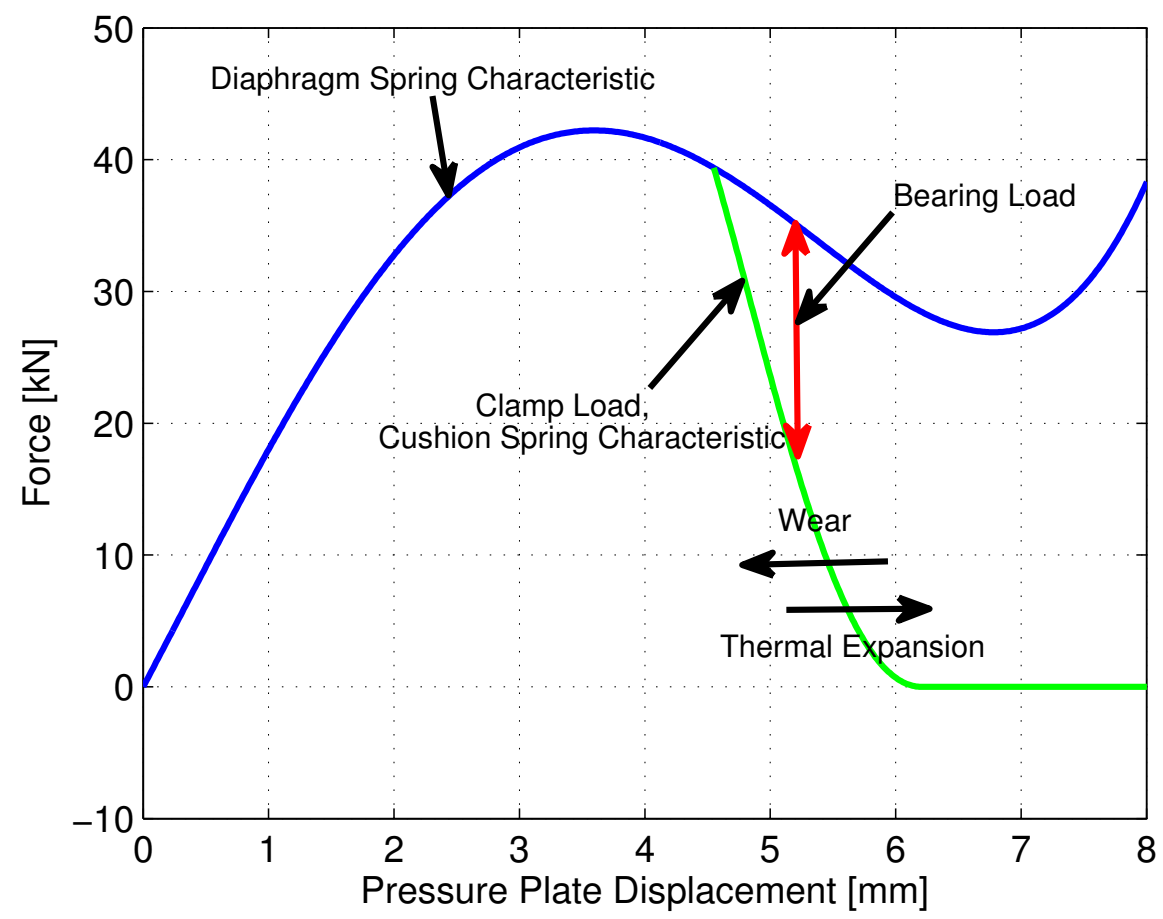

Figure 2.2: Illustration of how the two spring forces in the clutch and the throw-out bearing force interact. The diaphragm spring characteristic is the spring torque at the pivot point divided by the length of the lever between the pivot and the pressure plate. The throw-out bearing force is multiplied with the length of the lever between the bearing and the pivot and then divided with the length of the lever between the pivot and the pressure plate.

\subsection{The Idea of Micro Slip Control}

Unlike the slipping friction torque in the clutch, the engine torque is oscillatory, which can be seen in Figure 2.3. The ICE torque needs to be damped both for comfort reasons as well as for reducing the stress on driveline components (Reik et al., 1998). The classic solution to the damping problem is to put torsional springs, see Figure 2.1, and friction rings in either the clutch disc or a dual-mass flywheel. A new possibility, when the powertrain is equipped with an automatic clutch, is to damp the oscillations by continuously slipping the clutch. However, when slipping the clutch it will wear and energy is dissipated into the clutch, increasing the fuel consumption and possibly leading to clutch failure due to overheating. Therefore it is of great importance to keep the slip as low as possible, to have a "micro-slip". More background about micro-slip control is found in Section 2.4. 

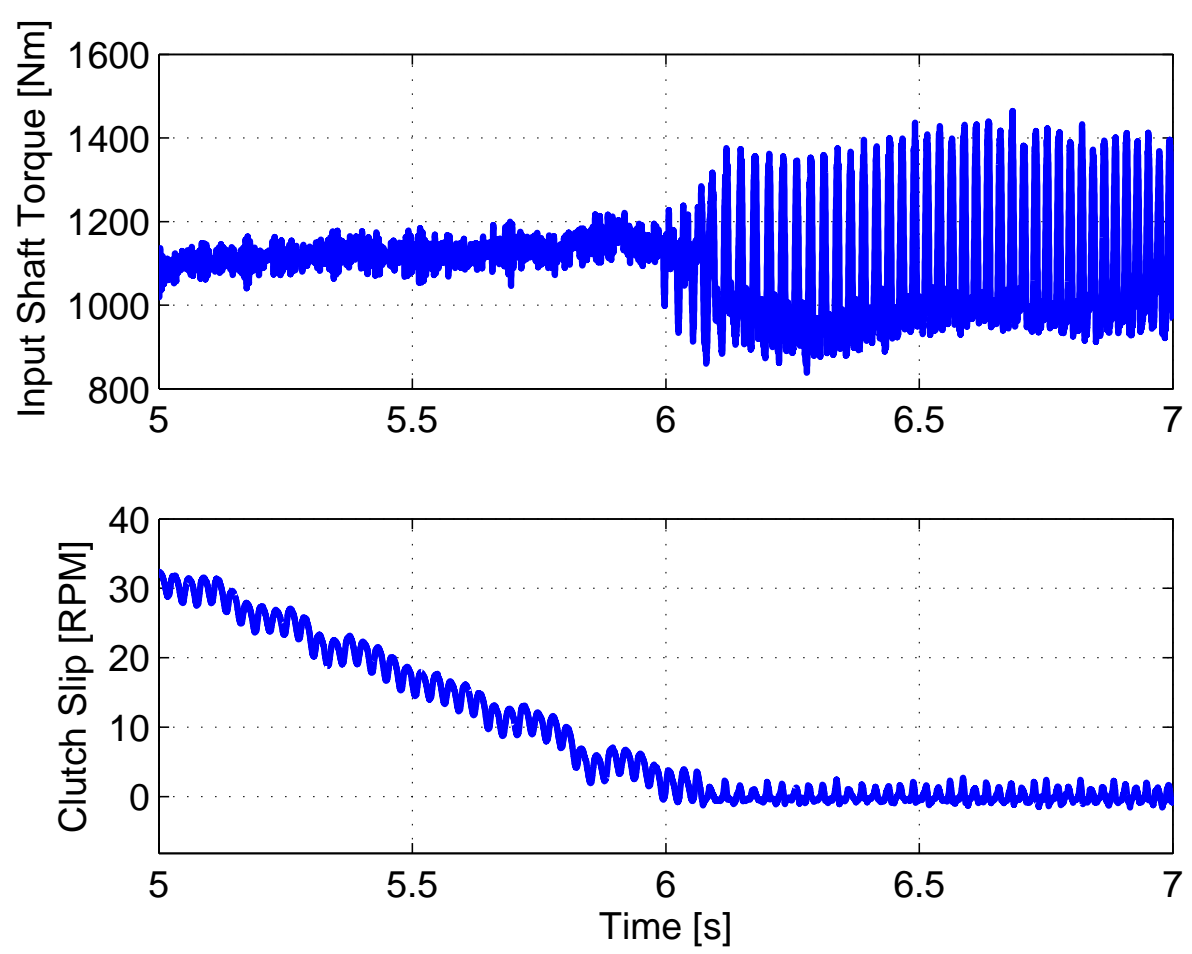

Figure 2.3: High resolution measurement of the clutch slip and a transmission input shaft torque sensor. The oscillations in the input shaft torque become significantly higher when the clutch locks up (zero slip speed) right after $6 \mathrm{~s}$.

\subsection{Review of Clutch And Driveline Models}

When modeling for control purposes not every detail has to be captured. It is sufficient if significant dynamics are captured and preferable if the model complexity can be kept low (Ljung, 1999). In the case of the clutch the transmitted torque is an important quantity to model. However, the importance of clutch torque control becomes clearer if it is put into the wider context of driveline control. For advanced driveline control, a driveline model is useful, either for simulation during development or for model based control. The model should capture the dynamics in the driveline, such as shunt and shuffle, that affects the comfort of the driver (and the passengers) (Eriksson and Nielsen, 2014).

\subsubsection{Driveline Models}

When modeling for control purposes it is common in the literature to include one or more flexibilities. In Pettersson (1997); Eriksson and Nielsen (2014); 
and Pettersson and Nielsen (2003) active shuffle damping and clutch-less gearshift control is studied. There the model includes flexibilities in the clutch, propeller shaft and drive shafts. The clutch torsion springs are modeled both in a linear and a piece-wise linear fashion. Also Fredriksson and Egardt (2003) and Pettersson and Nielsen (2000) looks at clutch-less gear-shift control, but this time only the drive-shaft flexibility is modeled. Garofalo et al. (2002) and Dolcini et al. (2008) study optimal control of clutch engagement. The former models two flexibilities in the driveline, one before the transmission and one after. Whereas, the latter models only the flexibility after the gearbox. A clutch-by-wire system is built in Moon et al. (2004), there a non-linear clutch and drive-shaft flexibilities are used. Clutch judder is examined in Crowther et al. (2004) using a driveline model with two flexibilities. A paper about AMT modeling in general (Lucente et al., 2007), states that three flexibilities are useful, one in the engine, one before the transmission, and one after.

\subsubsection{Clutch Models}

A wide range of models have been proposed in the literature. The most simple models have a clutch torque that is assumed to be a controllable input, see for example Dolcini et al. (2008) or Garofalo et al. (2002). These models rely on the assumption that there is perfect knowledge of how the clutch behaves. More advanced models include submodels for slipping and sticking torques. For example a LuGre model is used in Dolcini et al. (2005) and a Karnopp model in Bataus et al. (2011). The former is a one-state model that captures stick-slip behavior, varying break-away force, Stribeck effect, and viscous friction. The latter includes a dead-zone around zero speed to ease the simulation of stick-slip behavior. The clutch torque during slipping is commonly modeled using a function with the following structure

$$
M_{\mathrm{trans}, \mathrm{k}}=\operatorname{sgn}(\Delta \omega) n \mu R_{e} F_{N}
$$

where $\Delta \omega$ is the clutch slip (speed), $n$ the number of friction surfaces, $\mu$ the friction coefficient, $R_{e}$ the effective radius and $F_{N}$ the clamping (normal) force. In these models $F_{N}$ is often either given as input or a static nonlinear function of clutch position, $x$, i.e. $F_{N}=F_{N}(x)$, see for example Vasca et al. (2011) or Glielmo and Vasca (2000). In particular Dolcini et al. (2010) mentions that a third-order polynomial is suitable to describe the connection between throwoutbearing position and clutch transmitted torque, mainly governed by the cushion spring characteristic. In Deur et al. (2012) $\mu$ is fitted to the following regression curve

$$
\begin{aligned}
\mu & =a_{0}+a_{1}\left(e^{-a_{2} \Delta \omega}-1\right) T_{b}+\left(a_{3}-a_{4} \ln (\Delta \omega)\right) T_{b}^{2} \\
& +\left(a_{5}-a_{6} \Delta \omega\right) F_{N}+a_{7} T_{b} F_{N}
\end{aligned}
$$

where $T_{b}$ is the temperature of the clutch body and assumed to be an input signal. $a_{0}-a_{7}$ are curve parameters. $F_{N}$ is mapped against actuator position 
and $T_{b}$ in Deur et al. (2012). More advanced FEM models of the clutch are also found in the literature. To name some: Nam et al. (2000) investigates the stresses in the diaphragm spring; Sfarni et al. (2008) has studied how the clutch-disc characteristics change with wear; and Cappetti et al. (2012b) examines the temperature effect on the cushion spring. Especially temperature distributions are popular to investigate using FEM. Both in clutch parts: Abdullah and Schlattmann (2012a) examines temperature distributions in clutch discs with different grooves; and Lee et al. (2007) investigates the temperature distribution in the pressure plate; and in the clutch as a whole: Abdullah and Schlattmann (2012b) and Sun et al. (2013). These FEM models point out interesting effects but are of little use here as the computational complexity is too high for control purposes.

In Velardocchia et al. (2000) and Wikdahl and Ågren (1999) simpler temperature models are established. However, these two models do not include the effect of the temperature on $M_{\text {trans,k }}$. The models in Velardocchia et al. (2000) and Wikdahl and Ågren (1999) could be combined with the model presented in Deur et al. (2012), where the clutch temperature is an input, in order to give the clutch torque. Although that approach requires a map of the normal force as function of actuator position and temperature, whereas the approach in Paper A, (Myklebust and Eriksson, 2012b), is completely model based. Furthermore, the clamping load and temperatures, which are not available in production vehicles, need to be measured during the parameter estimation procedure. In Paper A, (Myklebust and Eriksson, 2012b), only sensors available in production vehicles are used.

\subsection{Introduction to Micro-Slip Control}

The idea of micro-slip control in AMTs has been around for over 20 years (Albers, 1990), but the amount of literature on the subject is limited. In Albers (1990) a slip control system and its capability of isolating the driveline from engine oscillations are demonstrated. It is also concluded that the increase in clutch wear is not a problem as long as excessive temperatures are avoided. Furthermore it is seen that above a certain engine speed the vibration isolation is sufficient without micro-slip and slip control can therefore be turned off at high engine speeds. This functionality is confirmed to exist in a production solution in Audi of America (2001). Further confirmation is found in Fischer and Berger (1998) where excitation and resonance frequencies are studied. It is concluded that locking the clutch is not only sufficient for vibration oscillation at higher engine speeds, but also necessary. A further conclusion is that the hardware in the driveline's torsion damper can be simplified without sacrifice of comfort if micro-slip is used. Tests in passenger vehicles have been performed in Küpper et al. (2002) and the vibration isolation performance of a single-massflywheel slip-controlled vehicle is equal to that of a dual-mass flywheel equipped vehicle without slip control. Only a slight increase in wear was detected and fuel 
consumption was unchanged. The latter was possible since the smaller inertia of the single-mass flywheel contributed to a lower fuel consumption.

Slip control is also of interest for ATs. To improve the efficiencies of ATs a lock-up clutch (or Torque Converter Clutch (TCC)) is employed, inside the Torque Converter (TC), that is capable of locking the pump to the turbine and thereby reducing the slip losses. Micro-slip is used for the TCC as well to allow a larger lock-up range and thereby improved fuel efficiency (Hiramatsu et al., 1985; Otanez et al., 2008). Both advanced control strategies, e.g. Higashimata et al. (2004), and more straight forward strategies, e.g. Hebbale et al. (2011), have been implemented and tested in passenger vehicles. In Higashimata et al. (2004) the TC is modeled as a linear parameter varying system and a feedforward link together with a $\mu$-synthesis feedback link is used to control the slip speed of the TCC. The controller is further developed using gain scheduling in Kaneko et al. (2009) and coasting capabilities are introduced in Katsumata et al. (2008). In Hebbale et al. (2011) model-based feedforward and slip-references-signal smoothing are used in order to get smooth slip control. Although there are similarities between slip control in an AT and an AMT the two are quite different. In an AT there is a second path for the torque, through the nonlinear TC, which is not present in an AMT. Moreover, the actuators are different and AMTs have less heat capacity. 



\section{Chapter 3}

\section{Experimental Observations and Model Structure}

This chapter presents a chain of experiments, considerations, and literature comparisons leading to the model structure used in the thesis.

\subsection{Experimental Platform}

As seen in Chapter 2, there are different ways to model the clutch. In order to choose a suitable model structure an experimental platform and data are required. Here Scania Heavy Duty Trucks (HDTs) with standard production sensors are used. A variety of trucks have been used but the two most used are Ara and Ernfrid. Both are equipped with a 14-speed AMT and a 16.4 liter V8 capable of producing $3500 \mathrm{Nm}$. Ara weighs 105 tonnes and Ernfrid 21 tonnes. The clutch was described in Chapter 2. A list of the measurement signals used can be found in Table 3.1 and their respective location in the driveline can be seen in Figure 3.1. The special case of a torque sensor in the powertrain is

Table 3.1: A list over the different measurements used in the HDTs

\begin{tabular}{c|l} 
Notation & Explanation \\
\hline$\omega_{e}$ & Engine speed \\
$\omega_{t}$ & Transmission input-shaft speed \\
$\omega_{p}$ & Transmission output-shaft speed \\
$\omega_{w}$ & Tractive-wheel speed \\
$v$ & Vehicle speed, actually speed of the free rolling (front) wheels \\
$T_{\text {coolant }}$ & Engine coolant temperature \\
$T_{\text {amb }}$ & Ambient temperature \\
$x_{m}$ & Clutch actuator motor position \\
$x_{p}$ & Clutch actuator piston position \\
$M_{e}$ & Engine torque, reported from ECU
\end{tabular}




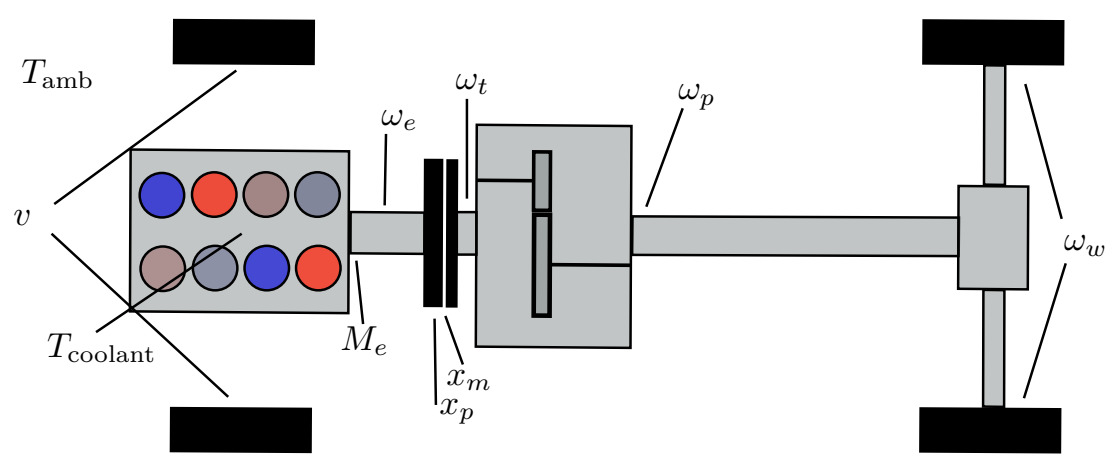

Figure 3.1: Sketch of a typical HDT driveline and where the sensors are located. See Table 3.1 for an explanation of the notation.

only studied in Paper D, (Myklebust and Eriksson, 2014b). So in order to get a measurement of the clutch torque, the reported engine torque is used with added compensation for inertia effects of the engine and flywheel.

The main benefit of this setup, with only production sensors, is that the resulting model and observer are directly applicable on a production HDT. Furthermore, the developed procedure for experiments, model building, model validation, and observer evaluation can easily be performed on other vehicles equipped with a dry clutch. On the other hand, the drawback, compared to a test stand, e.g. Velardocchia et al. (1999); Moon et al. (2004) or Deur et al. (2012), is fewer and less precise sensors. All the cited test stands consist of a stand-alone dry clutch that is cooled towards the stagnated room-temperature air. In a truck there might be an airflow, the clutch is installed below the truck floor, bolted to the transmission, and especially the flywheel is bolted to a 1 tonne, $\sim 90{ }^{\circ} \mathrm{C}$ warm engine. Naturally all this leads to different temperature dynamics.

\subsection{Motivating Experiment}

As a first investigation of the clutch characteristics the actuator position has been ramped back and forth several times while the clutch torque has been measured. Every second ramp pair the actuator has moved a shorter path. This is performed in order to study possible hysteresis effects. The results from such an experiment is presented in Figure 3.2. There the ramps are seen to follow a curve that can be fitted to a third order polynomial (Dolcini et al., 2010; Myklebust and Eriksson, 2012b). However, the polynomial is different for each ramp; there is clearly some dynamics present. 


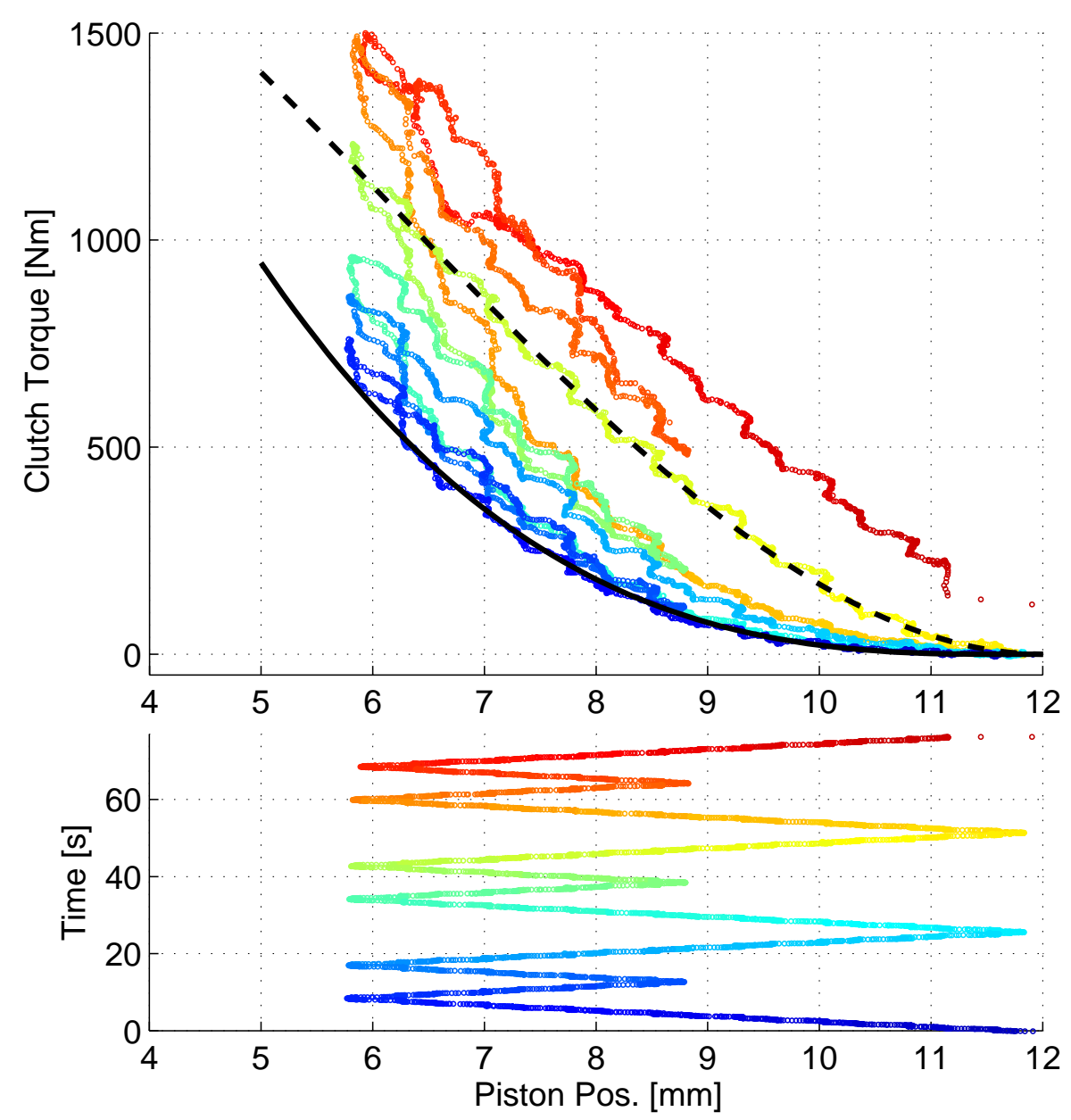

Figure 3.2: The clutch position, $x$, has been ramped back and forth while the clutch torque has been measured, top plot. The transmitted torque clearly depends on something more than the clutch position, in particular there is a drift with time. The time scale can be viewed by following the position into the lower plot. The time scale is also color coded: blue $=0 \mathrm{~s}$ and red $=75 \mathrm{~s}$. The torque difference between the first and last ramp is up to $900 \mathrm{Nm}$. The two black lines represent two possible parameterizations of a third order polynomial.

\subsection{ACtuator Dynamics}

The clutch actuator has a built-in position controller. This has the benefit that effects causing hysteresis in the actuator force, e.g. friction or the diaphragm spring, will not affect the actuator output/clutch torque relation (Deur et al., 2012). Furthermore, a position measurement of the piston effectively makes 


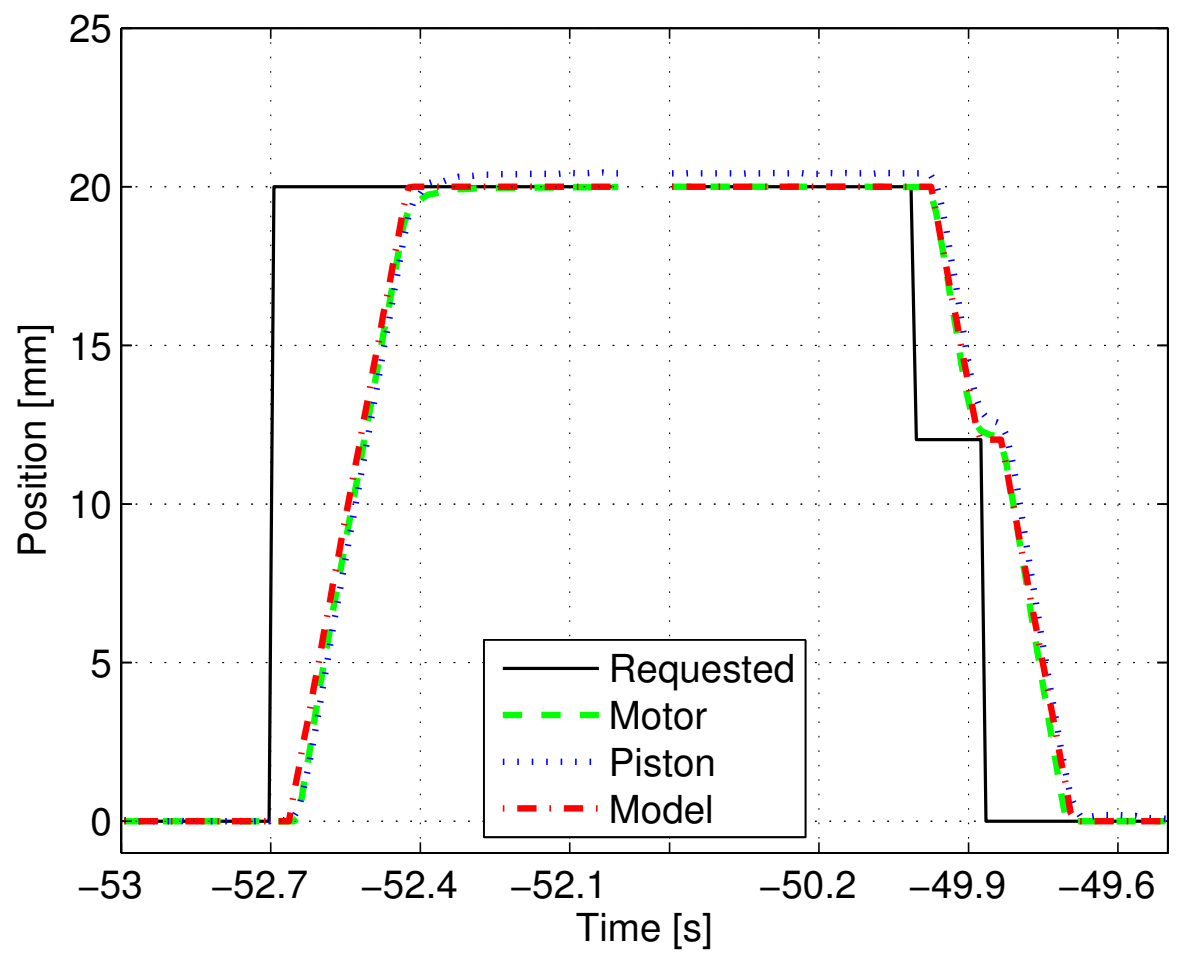

Figure 3.3: A step change in actuator (motor) position has been demanded. The corresponding response in both motor and piston position can be seen. The actuator is fast and can be modeled as a rate limiter of $84 \mathrm{~mm} / \mathrm{s}$ and a time delay of $0.03 \mathrm{~s}$.

the piston position the output of the actuator. Since the actuator output is known the clutch torque can be modeled without knowing the actuator dynamics. However, for control applications the limitations of the actuator need to be considered. Conveniently the motor in the actuator is both accurate and fast, see Figure 3.3. The motor position can therefore be modeled as the requested position rate limited to $84 \mathrm{~mm} / \mathrm{s}$ and delayed $0.03 \mathrm{~s}$.

Some dynamics exists in the hydraulics of the actuator but the piston still moves at approximately the same rate as the motor, so control of the piston position has similar performance. During intense use of the clutch the hydraulic oil can be heated and thereby expand. This will cause a change in the relation between the motor and piston position. However, since the piston position is measured and controlled, this is of small concern. It should be noted that the clutch is located inside the bell housing (the housing surrounding the clutch) whereas the actuator is outside the bell housing. The temperature dynamics of the actuator has therefore little to do with the temperature dynamics of the clutch discussed in Section 3.8. 


\subsection{Clutch Variables}

Several factors could be the reason for the dynamics seen in Figure 3.2. First lets recall (2.1) from the previous chapter

$$
M_{\mathrm{trans}, \mathrm{k}}=\operatorname{sgn}(\Delta \omega) n \mu R_{e} F_{N}
$$

Looking at (3.1) one factor that directly affects the clutch torque is the clamp load. The clamp load is dependent on the actuator position but also on other factors, mainly the cushion spring characteristic. This characteristic is reported to have a decreasing slope with temperature in Cappetti et al. (2012a). However, in Cappetti et al. (2012b) thermal expansion in the axial direction of the spring is shown to be a more significant effect. Sfarni et al. (2008) reports about steeper cushion spring characteristic with wear. From a graph in Hong et al. (2012) the normal force can be seen to be speed dependent. The speed dependency is said to be due to centrifugal forces acting on the diaphragm spring in Dolcini et al. (2010). The works Mashadi and Crolla (2012); Moon et al. (2004); and Szimandl and Németh (2012) report of hysteresis in the diaphragm spring, which could lead to hysteresis in the normal force. A decrease in diaphragm spring force with temperature is reported in Sun et al. (2013). The decrease is especially pronounced for temperatures above $200{ }^{\circ} \mathrm{C}$. In Mattiazzo et al. (2002) a temperature and wear dependency of the normal force/bearing position characteristics is shown. The wear is reported to affect the characteristics both through thinning of the disc, as in Figure 2.2, and through fatigue of the diaphragm spring. In Mattiazzo et al. (2002) the normal force decreases with temperature. In Deur et al. (2012); Cappetti et al. (2012b); and Hoic et al. (2013) the change in normal force/bearing position characteristics is explained by thermal expansion of clutch parts. The normal force is increasing with temperature, although with an exception for low forces in Hoic et al. (2013). There the normal force is decreasing with temperature due to the expansion of a return spring, which is not present in the more common setup studied here.

However, the normal force is not the only component of (3.1) that varies. It is generally recognized that $\mu$ can depend on temperature, slip speed, and wear while $R_{e}$ can depend on temperature and wear as well (Velardocchia et al., 1999; Sun et al., 2013). Sun et al. (2013) has data showing an increase of $\mu$ with temperature up to $200{ }^{\circ} \mathrm{C}$, after that $\mu$ decreases. In Vasca et al. (2011) a slip speed dependency of $\mu R_{e}$ is shown, this was especially pronounced for slip speeds below $\sim 100$ RPM. $R_{e}$ has been assumed constant in Deur et al. (2012), and there $\mu$ decreases with temperature and increases with slip for a low to medium normal force but for a high normal force no clear trend is seen. The result is explained using (2.2).

It can be difficult to separate which parameter in (3.1) that is the reason for a change in $M_{\text {trans,k }}$. The clutch torque is therefore often studied as a lumped model. In Velardocchia et al. (1999) $M_{\text {trans,k }}$ is seen to decrease with temperature and $\Delta \omega$. However, there are large variations with wear. In Ercole et al. (2000) $M_{\text {trans,k }}$ initially decreases with temperature for low temperatures and then 
increases for medium and high temperatures. Similarly there are variations with wear, and in addition, temperature-torque hysteresis are reported.

A summary of the effects and dependencies above is to express (3.1) as

$$
M_{\text {trans }, \mathrm{k}}=\operatorname{sgn}(\Delta \omega) n \mu(\Delta \omega, T, t) R_{e}(T, t) F_{N}\left(x, T, \omega_{e}, t\right)
$$

where $T$ is the temperature(s) and $t$ represents wear (with time). Since production trucks are used as experimental platforms, the number of sensors is limited. This reduces the possibilities to separate the effects in (3.2). Therefore a lumped model has been studied here

$$
M_{\text {trans }, \mathrm{k}}=M_{\text {trans }, \mathrm{k}}\left(\Delta \omega, \omega_{e}, T, t, x\right)
$$

However, the more general model (3.2) gives some insight that can be used for setting up experiments and selecting the internal structure of the model (3.3). In the following sections, experiments useful for investigation of the clutch torque are described together with their results. The experiments have been designed to isolate different effects from each other and to step through the dependencies of $(3.3)$.

\subsection{WEAR}

Investigations of wear require a lot of time consuming measurements. Luckily wear is usually a slow process that is not noticeable in single experiments. Wear is therefore omitted from the model structure

$$
M_{\text {trans, } \mathrm{k}}=M_{\text {trans,k }}\left(\Delta \omega, \omega_{e}, T, x\right)
$$

However, in a production application wear has to be dealt with through e.g. adaptation. The only wear effect that has been observed throughout this thesis is thinning of the clutch disc. A method for adapting the disc thickness is proposed in Paper C, (Myklebust and Eriksson, 2014a).

\subsection{SLIP}

In order to investigate the slip-speed dependency experiments have been carried out as follows. A truck has been driven to an uphill and has been kept stationary by slipping the clutch at a constant position. This way the vehicle will accelerate forwards if more torque is transmitted and backwards if less torque is transmitted. Furthermore, it is easy, at least initially, to keep the input-shaft speed stationary this way, and by doing so the engine speed can be used to control the slip speed. The change in slip speed will of course have a corresponding change in dissipated power and hence the temperature rate. In order to isolate the slip dependency from temperature dynamics a fast change in slip speed is desirable. Slip-speed steps are therefore made and an abrupt change in torque/input-shaft 

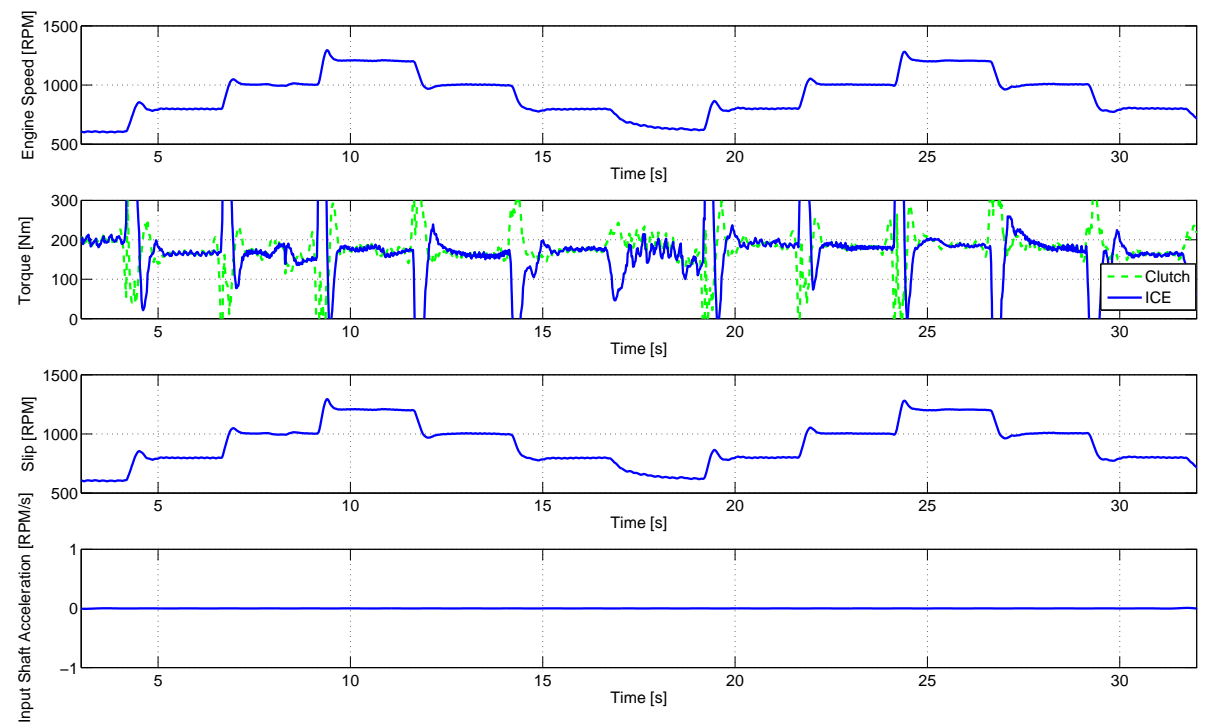

Figure 3.4: Slip steps are made through engine-speed control when the truck is held stationary in a slight uphill using a constant clutch position. No reaction is seen in neither clutch torque nor input shaft acceleration.

acceleration should be seen if there is a slip-speed dependency, see Figure 3.4. Note that the engine torque has a transient during the edges of a step, due to the acceleration of the engine. A smaller transient is present in the clutch torque signal due to imperfections in the compensation for the acceleration. No significant change is seen in the input-shaft acceleration and no correlation between steady-state clutch torque and slip speed is seen neither, see Figure 3.5. Based on this experiment (3.4) can be reduced to

$$
M_{\mathrm{trans}, \mathrm{k}}=M_{\mathrm{trans}, \mathrm{k}}\left(\omega_{e}, T, x\right)
$$

This is somewhat in contrast to the data in Velardocchia et al. (1999) where a slip dependency is shown. The slip has only been investigated at relatively large speeds and does therefore not contrast the data in Vasca et al. (2011) where the slip dependency only is present below $100 \mathrm{RPM}$.

\subsection{Rotational Speed}

Centrifugal effects in the diaphragm spring can be studied with the same experiment as in Section 3.6 since the engine speed (and thereby diaphragm spring speed) is varied whereas the other parameters of (3.5) are kept constant. Hence no effects are seen in the torque in Figure 3.4, no speed dependency is 


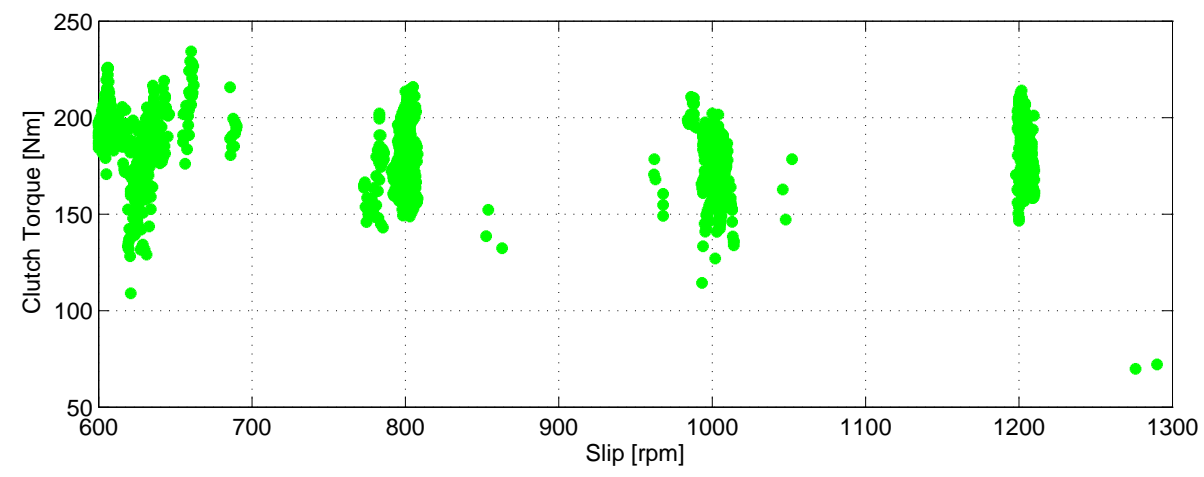

Figure 3.5: The data points from Figure 3.4 when the engine speed is constant. No correlation is seen between clutch torque and slip speed.

present either. The model can be further simplified into

$$
M_{\text {trans,k }}=M_{\text {trans,k }}(T, x)
$$

There is a risk that an effect of $\omega_{e}$ is present but canceled by an effect of $\Delta \omega$. In order to fully investigate this the experiment of Section 3.6 would need to be repeated with different input-shaft speeds, which would give different combinations of slip speed and engine speed. This kind of experiment has not been performed due to practical difficulties with controlling the input-shaft speed to a constant non-zero value.

\subsection{TEMPERATURE}

A variation of the experiment of Section 3.6 can be used to isolate the thermal effect. The truck is placed in an uphill and the clutch is controlled to a point where it can keep the truck stationary. Movement of the truck is not desirable as it can make the clutch lock up (and the slip to vary). The dissipated power will heat the clutch and if that affects the transmitted torque the truck will start to move unless the clutch position is controlled to maintain a constant torque. Therefore the clutch torque is put under feedback and the clutch position is measured. In Figure 3.6 the position is seen to increase as more energy is dissipated into the clutch. There is clearly some temperature dynamics present.

When performing experiments for identifying the thermal dynamics the cool down process is also of interest. However, a position that transmits a slipping torque can not be measured if the clutch is to cool down. One possibility then is to investigate how the kiss point, where pressure plate and clutch disc first meet, changes with cooling. This feels intuitive as the kiss point is an important parameter in clutch control. However, due to inexactness in the torque measurement and the cushion spring characteristic of the clutch 

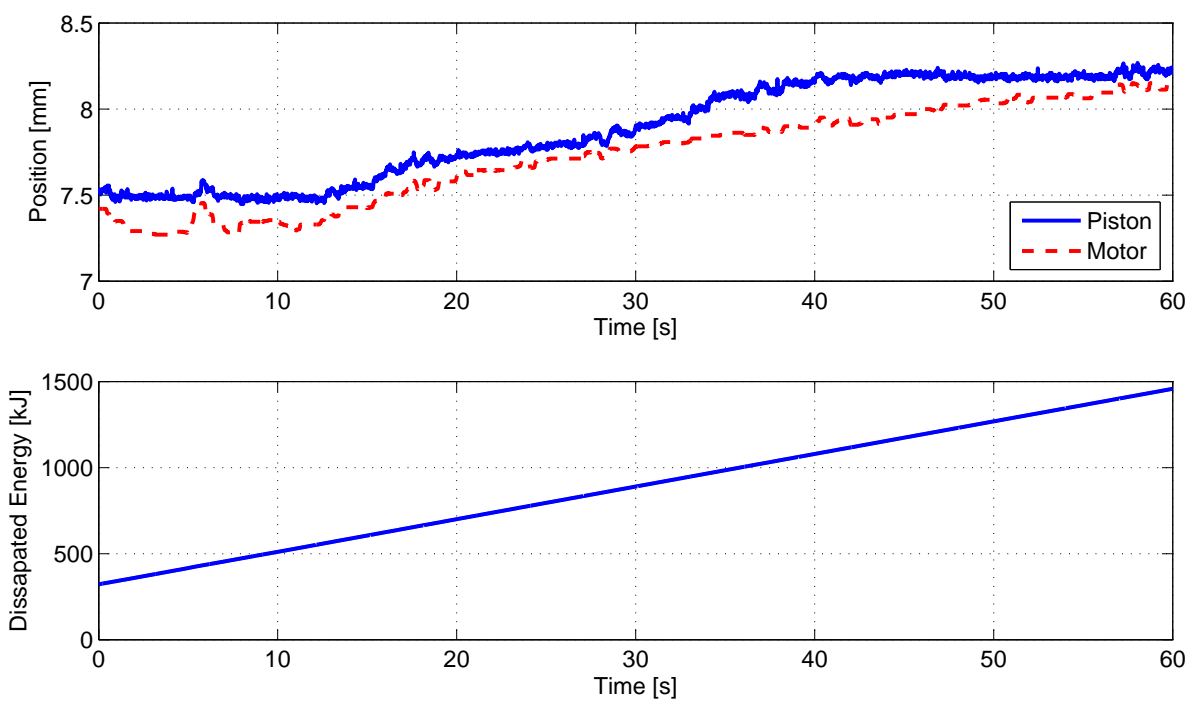

Figure 3.6: Slip and torque through the clutch have been held constant. To keep them constant the clutch position has to be varied. The motor position and piston position vary differently. The position increases with dissipated energy.

transmissibility curve around zero torque, the exact position of the kiss point is hard to detect. One way to ease the detection is to engage the clutch when neutral gear is engaged. This way the input-shaft speed will respond to the transmitted torque quickly. Experiments of this type have shown that the kiss point varies sporadically, see Figure 3.7. This is thought to be because the clutch disc can slide axially along the transmission input-shaft and stop in an arbitrary position in the gap between pressure plate and flywheel. The friction along the shaft can provide a sufficient clamp load to transfer enough torque to spin the input shaft when in neutral gear, but not enough to transmit any significant torque for the truck dynamics. Therefore the exact value of the kiss point is not of great concern, instead the point where clutch torque gets significant is of greater concern.

An alternative measure is the position where the clutch is fully closed, here called the zero position. This point is easy to determine, when the actuator motor is fully backed out (motor position zero, hence the name zero position) the clutch will, due to the diaphragm spring, be fully closed. If the clutch is closed when neutral gear is engaged, no significant energy is dissipated into the clutch. The zero position does therefore give a more stable measurement, see Figure 3.7. The zero position increases when heat is dissipated into the clutch and it decreases exponentially when no heat is dissipated. A hypothesis is that thermal expansion of the clutch is the reason for the change in zero position. Therefore a rough estimate of the thermal expansion has been made as follows: 
The clutch mass is estimated as the flywheel and pressure plate, $m_{c}=$ $m_{f w}+m_{p p}=47+34=81 \mathrm{~kg}$. They are made out of cast iron, and according to Nording and Österman (1999) the expansion coefficient is $e_{c i}=11 \cdot 10^{-6} 1 / \mathrm{K}$, and the specific heat capacity is, $c_{p}=500 \mathrm{~J} /(\mathrm{kg} \mathrm{K})$. If $4 \mathrm{MJ}$ of energy is dissipated into the clutch through slipping, as in Figure 3.7, the clutch will heat up with approximately $98 \mathrm{~K}$ and expand by $0.11 \%$. The clutch is about $100 \mathrm{~mm}$ thick, which means it will expand by $0.11 \mathrm{~mm}$. At the actuator this is seen as $0.96 \mathrm{~mm}$ (ratio of 8.8 measured in drawings). When comparing this number with the change in the zero position seen in Figure 3.7, the numbers are in the same order of magnitude. During the warm up the zero position increases with $\sim 1.2 \mathrm{~mm}$ and during cool down it decreases $\sim 0.8 \mathrm{~mm}$ asymptotically. This gives further support for the hypothesis that this effect is due to the thermal expansion of the clutch.

In order to observe the zero position, not only when the clutch is cooling but also when the clutch is heated, the following procedure has been used. The clutch has been slipped for a short time while the truck has been in gear and kept stationary by the parking brake. After the slipping phase the clutch has been closed in neutral gear so that the zero position can be measured. The slipping phase and the measurement phase are alternated like this for an extended period of time. The result of such an experiment can be seen in Figure 3.8. A two-state temperature model can be fitted to this data, see Paper A, (Myklebust and Eriksson, 2012b), or Paper C, (Myklebust and Eriksson, 2014a), for details.

However, if the dynamics seen in Figure 3.8 is compared to those seen in Figure 3.6 two things can be noticed: First, the change in position is much larger in Figure 3.6. Second, the time constant in Figure 3.6 is much smaller. This smaller time constant could correspond to a smaller thermal mass, e.g. the clutch disc. The thermal behavior of the cushion spring inside the clutch disc is investigated in Cappetti et al. (2012b) and could explain the faster dynamics seen here. A third temperature state with faster dynamics is useful in order to explain the clutch thermal dynamics, again see Paper A, (Myklebust and Eriksson, 2012b), or Paper C, (Myklebust and Eriksson, 2014a), for details.
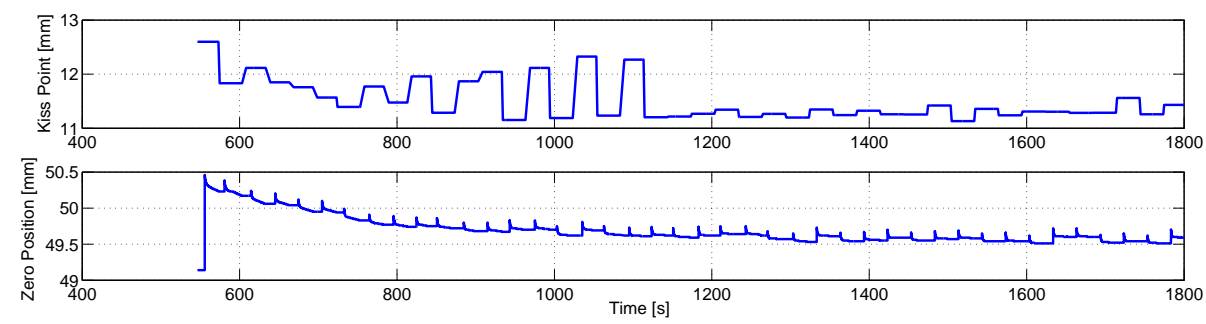

Figure 3.7: About 4 MJ of energy has been dissipated in the clutch. Afterwards the truck has been standing still with neutral gear engaged while the kiss point and zero position have been monitored. 


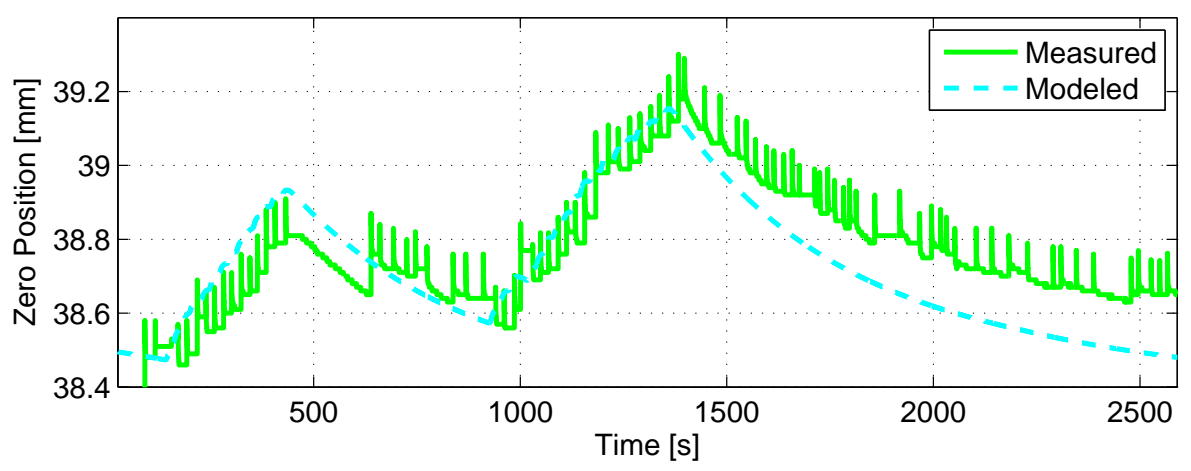

Figure 3.8: The clutch has been heated through slipping and then left to cool down. The zero position has been recorded as a measure of the expansion. A two-state temperature model can explain the data.

The temperature dynamics consists of three temperatures and in common for all of them is that energy is gained through the power dissipated in the clutch

$$
P=M_{\text {trans,k }} \Delta \omega
$$

and energy is dissipated to the ambient air and to the ICE, but not so much to the transmission (Wikdahl and Ågren, 1999). Since the truck is moving and the clutch is spinning there will be forced convection. Therefore the vehicle and clutch speed are also possible variables

$$
\dot{T}=f\left(T, P, T_{\mathrm{ICE}}, T_{\mathrm{amb}}, \omega_{e}, v\right)
$$

where $T$ is a temperature vector, $T_{\mathrm{ICE}}$ is the coolant temperature of the ICE, $T_{\mathrm{amb}}$ is the ambient temperature and the engine speed is used as clutch speed.

\subsubsection{Vehicle Speed Dependency}

The speed of the truck directly affects the speed by which air is flowing past the bell housing. This forced convection will naturally increase the cooling of the clutch. In most experiments performed here, the truck has been held stationary in order to keep the clutch from locking up. Although, this should be of smaller concern when using the observer of Paper C, (Myklebust and Eriksson, 2014a), since the bell housing temperature only affects the clutch torque indirectly through the ambient conditions of the flywheel and pressure plate. Equation (3.8) can be reduced to

$$
\dot{T}=f\left(T, P, T_{\mathrm{ICE}}, T_{\mathrm{amb}}, \omega_{e}\right)
$$




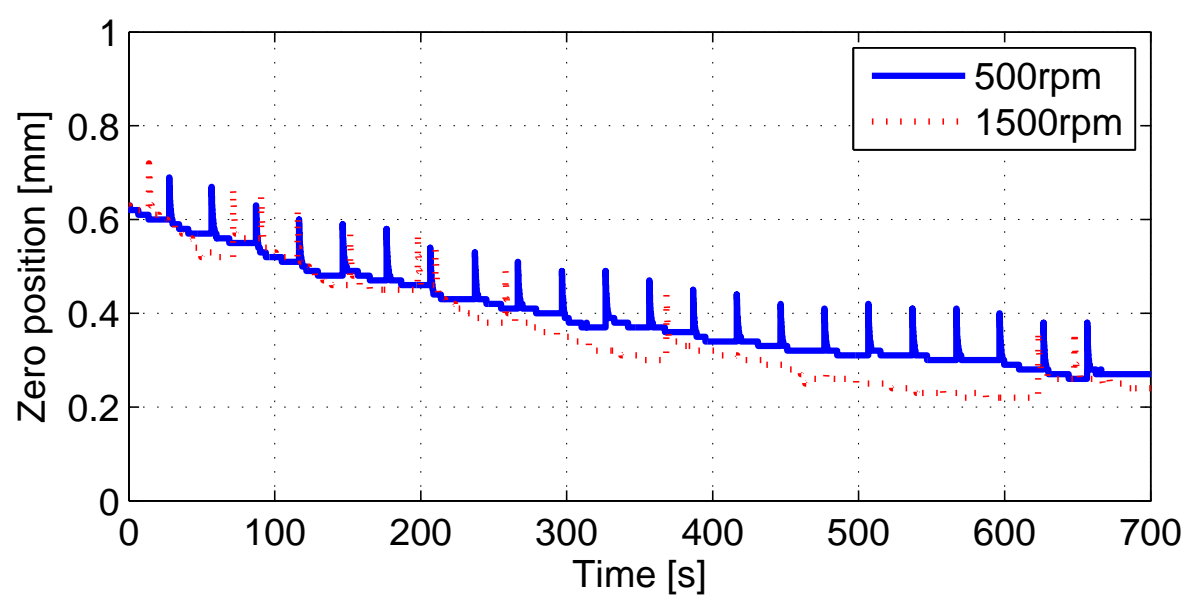

Figure 3.9: Zero position measurements when the clutch is cooling down. In one case the engine speed has been $500 \mathrm{RPM}$ and the coolant temperature has been $77^{\circ} \mathrm{C}$. In the other case the engine speed has been $1500 \mathrm{RPM}$ and the coolant temperature has been $82{ }^{\circ} \mathrm{C}$. The two trajectories are similar. The zero position has been adjusted with an offset to compensate for different wear levels in the two experiments.

\subsubsection{Engine Speed Dependency}

If the clutch is spinning at a higher speed there should be more forced convection and the clutch body should cool faster towards clutch housing temperatures. Experiments have therefore been carried out where the zero position has been measured during cooling of the clutch with two different engine speeds, and hence two different clutch body speeds. Looking at the data in Figure 3.9 there is no significant difference in the curve shapes indicating that the clutch speed has no significant effect on the clutch temperature. Therefore (3.8) can be further reduced to

$$
\dot{T}=f\left(T, P, T_{\mathrm{ICE}}, T_{\mathrm{amb}}\right)
$$

Using the observer from Paper C, (Myklebust and Eriksson, 2014a), it can be verified that both measurements start at the same temperature level. For the $500 \mathrm{RPM}$ case and the $1500 \mathrm{RPM}$ case the clutch body temperature is $109^{\circ} \mathrm{C}$ and $107^{\circ} \mathrm{C}$, respectively and the clutch housing temperature is $83^{\circ} \mathrm{C}$ and $85^{\circ} \mathrm{C}$, respectively. The engine coolant temperature was measured to $77^{\circ} \mathrm{C}$ and $82^{\circ} \mathrm{C}$, respectively. 


\subsection{Model Summary and Usage in Papers}

In this and the previous chapter a literature survey of dry-clutch models and experiments is summarized into the model structure (3.3). Thereafter a set of experiments is designed to investigate which variables in (3.3) that are significant. All experiments have been performed on production trucks driven on roads. Therefore this set of experiments can easily be adapted to new platforms. After performing the experiments the model structure is

$$
\begin{aligned}
\dot{T} & =f\left(T, P, T_{\mathrm{ICE}}, T_{\mathrm{amb}}\right) \\
M_{\text {trans }, \mathrm{k}} & =M_{\text {trans }, \mathrm{k}}(T, x)
\end{aligned}
$$

This model structure is developed and parameterized in Paper A, (Myklebust and Eriksson, 2012b), using the experiments described in this chapter. The model that results from Paper A, (Myklebust and Eriksson, 2012b), is the foundation for Paper B, (Myklebust and Eriksson, 2013), and Paper C, (Myklebust and Eriksson, 2014a). In Paper B, (Myklebust and Eriksson, 2013), simulations of the clutch model and the driveline model from Paper F, (Myklebust and Eriksson, 2012a), are used to demonstrate the importance of considering the thermal dynamics in clutch control applications. One way to do that is to build an observer using the model. This is done in Paper C, (Myklebust and Eriksson, 2014a), and Paper D, (Myklebust and Eriksson, 2014b), where a clutch torque and temperature observer is designed. In the latter paper the special case when a torque sensor is available in the driveline is studied. The observer from Paper C, (Myklebust and Eriksson, 2014a), is put to use in a micro-slip controller in Paper E, (Myklebust and Eriksson, 2014c). 


\section{REFERENCES}

Oday I. Abdullah and Josef Schlattmann. Finite element analysis for grooved dry friction clutch. Advances in Mechanical Engineering and its Applications, 2(1):2167-6380, 2012a.

O.I. Abdullah and J. Schlattmann. Finite element analysis of temperature field in automotive dry friction clutch. Tribology in Industry, 34(4):206-216, 2012b.

Albert Albers. Torque control isolation (TCI) the smart clutch. In 4 th $\mathrm{LuK}$ Symposium, 1990.

Inc. Audi of America. Variable automatic transmission multitronic 01j, August 2001. Self-Study Program Course Number 951103.

Marius Bataus, Andrei Maciac, Mircea Oprean, and Nicolae Vasiliu. Automotive clutch models for real time simulation. Proceedings of the Romanian Academy, Series A, 12(2):109-116, 2011.

Nicola Cappetti, Mario Pisaturo, and Adolfo Senatore. Modelling the cushion spring characteristic to enhance the automated dry-clutch performance: The temperature effect. Proc IMechE, Part D: Journal of Automobile Engineering, 226(11):1472-1482, 2012a.

Nicola Cappetti, Mario Pisaturo, and Adolfo Senatore. Cushion spring sensitivity to the temperature rise in automotive dry clutch and effects on the frictional torque characteristic. Mechanical Testing and Diagnosis, 3(2):28-38, 2012b.

A. Crowther, N. Zhang, D.K. Liu, and J.K. Jeyakumaran. Analysis and simulation of clutch engagement judder and stick-slip in automotive powertrain systems. Proc IMechE, Part D: Journal of Automobile Engineering, 218(12): 1427-1446, December 2004.

Josko Deur, Vladmir Ivanovic, Zvonko Herold, and Milan Kostelac. Dry clutch control based on electromechanical actuator position feedback loop. International Journal of Vehicle Design, 60(3-4):305-326, 2012.

Pietro Dolcini, Carlos Canudas de Wit, and Hubert Béchart. Improved optimal control of dry clutch engagement. Proceedings of the 16th IFAC World Congress, $16(1), 2005$.

Pietro Dolcini, Carlos Canudas de Wit, and Hubert Béchart. Lurch avoidance strategy and its implementation in AMT vehicles. Mechatronics, 18(1):289-300, May 2008.

Pietro J. Dolcini, Carlos Canudas de Wit, and Hubert Béchart. Dry Clutch Control for Automotive Applications. Advances in Industrial Control. SpringerVerlag London, 2010. 
G. Ercole, G. Mattiazzo, S. Mauro, M. Velardocchia, F. Amisano, and G. Serra. Experimental methodologies to determine diaphragm spring clutch characteristics. In SAE Technical Paper: 2000-01-1151, March 2000.

Lars Eriksson and Lars Nielsen. Modeling and Control of Engines and Drivelines. John Wiley \& Sons, 2014.

Robert Fischer and Reinhard Berger. Automation of manual transmissions. In 6th LuK Symposium, 1998.

Jonas Fredriksson and Bo Egardt. Active engine control for gear shifting in automated manual transmissions. International Journal of Vehicle Design, 32 (3-4):216-230, 2003.

Franco Garofalo, Luigi Glielmo, Luigi Iannelli, and Francesco Vasca. Optimal tracking for automotive dry clutch engagement. In 2002 IFAC, 15th Triennial World Congress, 2002.

Luigi Glielmo and Francesco Vasca. Optimal control of dry clutch engagement. In SAE Technical Paper: 2000-01-0837, March 2000.

Kumaraswamy Hebbale, Chunhao Lee, Farzad Samie, Chi-Kuan Kao, Xu Chen, Jeremy Horgan, and Scott Hearld. Model based torque converter clutch slip control. In SAE Technical Paper: 2011-01-0396, April 2011.

Akira Higashimata, Kazutaka Adachi, Satoshi Segawa, Nobuo Kurogo, and Hironobu Waki. Development of a slip control system for a lock-up clutch. In SAE Technical Paper: 2004-01-1227, April 2004.

Takeo Hiramatsu, Takao Akagi, and Haruaki Voneda. Control technology of minimal slip-type torque converter clutch. In SAE Technical Paper: 850460, February 1985.

Matija Hoic, Zvonko Herold, Nenad Kranjcevic, Josko Deur, and Vladimir Ivanovic. Experimental characterization and modeling of dry dual clutch thermal expansion effects. In SAE Technical Paper: 2013-01-0818, April 2013.

Sungwha Hong, Sunghyun Ahn, Beakyou Kim, Heera Lee, and Hyunsoo Kim. Shift control of a 2-speed dual clutch transmission for electric vehicle. In 2012 IEEE Vehicle Power and Propulsion Conference, October 2012.

Yutaka Kaneko, Kazutaka Adachi, Fumiyo Iino, and Mitsuo Hirata. Development of a slip speed control system for a lock-up clutch (part iii). In $S A E$ Technical Paper: 2009-01-0955, April 2009.

Yuji Katsumata, Satoshi Segawa, Kazutaka Adachi, and Akira Higashimata. Development of a slip speed control system for a lock-up clutch (part ii). In SAE Technical Paper: 2008-01-0001, April 2008. 
Klas Küpper, Roland Seebacher, and Olaf Werner. Think systems - software by LuK. In 7th LuK Symposium, 2002.

Choon Yeol Lee, Ilsup Chung, and Young Suck Chai. Finite element analysis of an automobile clutch system. Key Engineering Materials, 353-358(1):2707-2711, September 2007.

Lennart Ljung. System Identification Theory for the user. Prentice Hall Information ans System Sciences Series. Prentice-Hall, Inc, 2nd edition, 1999.

Gianluca Lucente, Marcello Montanari, and Carlo Rossi. Modelling of an automated manual transmission system. Mechatronics, 17(1):73-91, November 2007.

Behrooz Mashadi and David Crolla. Vehicle Powertrain Systems. John Wiley \& Sons Ltd, first edition, 2012.

G. Mattiazzo, S. Mauro, M. Velardocchia, F. Amisano, G. Serra, and G. Ercole. Measurement of torque transmissibility in diaphragm spring clutch. In $S A E$ Technical Paper: 2002-01-0934, March 2002.

S.E. Moon, M.S. Kim, H. Yeo, H.S Kim, and S.H Hwang. Design and implementation of clutch-by-wire system for automated manual transmissions. International Journal Vehicle Design, 36(1):83-100, 2004.

Andreas Myklebust and Lars Eriksson. Road slope analysis and filtering for driveline shuffle simulation. In 2012 IFAC Workshop on Engine and Powertrain Control, Simulation and Modeling, October 2012a.

Andreas Myklebust and Lars Eriksson. Torque model with fast and slow temperature dynamics of a slipping dry clutch. In 2012 IEEE Vehicle Power and Propulsion Conference, October 2012b.

Andreas Myklebust and Lars Eriksson. The effect of thermal expansion in a dry clutch on launch control. In 7th IFAC Symposium on Advances in Automotive Control, September 2013.

Andreas Myklebust and Lars Eriksson. Modeling, observability, and estimation of thermal effects and aging on transmitted torque in a heavy duty truck with a dry clutch. IEEE/ASME Transactions on Mechatronics, $\operatorname{PP}(99): 1-12,2014 \mathrm{a}$.

Andreas Myklebust and Lars Eriksson. Thermal clutch model observability and observer effects of a torque sensor in the powertrain. Submitted to IEEE/ASME Transactions on Mechatronics, 2014b.

Andreas Myklebust and Lars Eriksson. Dry clutch micro-slip control and temperature considerations. Submitted to IEEE/ASME Transactions on Mechatronics, 2014c. 
Wook-Hee Nam, Choon-Yeol Lee, Young S. Chai, and Jae-Do Kwon. Finite element analysis and optimal design of automobile clutch diaphragm spring. In Seoul 2000 FISITA World Automotive Congress, June 2000.

K. Newton, W. Steeds, and T K Garrett. The Motor Vehicle. ButterworthHeinemann, 1996.

Carl Nording and Jonny Österman. Physics Handbook. Studentlitteratur, 1999.

M.J. Nunney. Automotive Technology. Butterworth-Heinemann, third edition, 1998.

Paul Otanez, Farzad Samie, Chunhao Joseph Lee, and Chi-Kuan Kao. Aggressive torque converter clutch slip control and driveline torsional velocity measurements. In SAE Technical Paper: 2008-01-1584, April 2008.

Magnus Pettersson. Driveline Modeling and Control. PhD thesis, Linköpings Universitet, May 1997.

Magnus Pettersson and Lars Nielsen. Gear shifting by engine control. IEEE Transactions Control Systems Technology, 8(3):495-507, May 2000.

Magnus Pettersson and Lars Nielsen. Diesel engine speed control with handling of driveline resonances. Control Engineering Practice, 11(3):319-328, March 2003.

Wolfgang Reik, Roland Seebacher, and Ad Kooy. Dual mass flywheel. In 6th LuK Symposium, 1998.

Samir Sfarni, Emmanuel Bellenger, Jérome Fortin, and Matthieu Malley. Numerical modeling of automotive riveted clutch disc for contact pressure verification. In 49th Scandinavian Conference on Simulation and Modeling, October 2008.

Shaohua Sun, Yulong Lei, Yao Fu, Cheng Yang, and ShunBo Li. Analysis of thermal load for dry clutch under the frequent launching condition. In $S A E$ Technical Paper: 2013-01-0814, April 2013.

Barna Szimandl and Huba Németh. Dynamic hybrid model of an electropneumatic clutch system. Mechatronics, 23(1):21-36, 2012.

Francesco Vasca, Luigi Iannelli, Adolfo Senatore, and Gabriella Reale. Torque transmissibility assessment for automotive dry-clutch engagement. IEEE/ASME transactions on Mechatronics, 16(3):564-573, June 2011.

M. Velardocchia, G. Ercole, G. Mattiazzo, S. Mauro, and F. Amisano. Diaphragm spring clutch dynamic characteristic test bench. In SAE Technical Paper: 1999-01-0737, March 1999.

M. Velardocchia, F. Amisano, and R. Flora. A linear thermal model for an automotive clutch. In SAE Technical Paper: 2000-01-0834, March 2000. 
Anna Wikdahl and Åsa Ågren. Temperature distribution in a clutch. Master's thesis, Linköping University, 1999. 
Publications 



\section{Publications}

The articles associated with this thesis have been removed for copyright reasons. For more details about these see:

http://urn.kb.se/resolve?urn=urn:nbn:se:liu:diva-108838 


\section{Linköping studies in science and technology, Dissertations Division of Vehicular Systems Department of Electrical Engineering Linköping University}

No 1 Magnus Pettersson, Driveline Modeling and Control, 1997.

No 2 Lars Eriksson, Spark Advance Modeling and Control, 1999.

No 3 Mattias Nyberg, Model Based Fault Diagnosis: Methods, Theory, and Automotive Engine Applications, 1999.

No 4 Erik Frisk, Residual Generation for Fault Diagnosis, 2001.

No 5 Per Andersson, Air Charge Estimation in Turbocharged Spark Ignition Engines, 2005.

No 6 Mattias Krysander, Design and Analysis of Diagnosis Systems Using Structural Methods, 2006.

No 7 Jonas Biteus, Fault Isolation in Distributed Embedded Systems, 2007.

No 8 Ylva Nilsson, Modelling for Fuel Optimal Control of a Variable Compression Engine, 2007.

No 9 Markus Klein, Single-Zone Cylinder Pressure Modeling and Estimation for Heat Release Analysis of SI Engines, 2007.

No 10 Anders Fröberg, Efficient Simulation and Optimal Control for Vehicle Propulsion, 2008.

No 11 Per Öberg, A DAE Formulation for Multi-Zone Thermodynamic Models and its Application to CVCP Engines, 2009.

No 12 Johan Wahlström, Control of EGR and VGT for Emission Control and Pumping Work Minimization in Diesel Engines, 2009.

No 13 Anna Pernestål, Probabilistic Fault Diagnosis with Automotive Applications, 2009.

No 14 Erik Hellström, Look-ahead Control of Heavy Vehicles, 2010.

No 15 Erik Höckerdal, Model Error Compensation in ODE and DAE Estimators with Automotive Engine Applications, 2011.

No 16 Carl Svärd, Methods for Automated Design of Fault Detection and Isolation Systems with Automotive Applications, 2012.

No 17 Oskar Leufvén, Modeling for control of centrifugal compressors, 2013. 
No 18 Christofer Sundström, Model Based Vehicle Level Diagnosis for Hybrid Electric Vehicles, 2014.

No 19 Andreas Thomasson, Modeling and control of actuators and co-surge in turbocharged engines, 2014.

No 20 Emil Larsson, Model Based Diagnosis and Supervision of Industrial Gas Turbines, 2014. 